\title{
Dynamic Analysis of Duopoly Price Game Based on Low-Carbon Technology Sharing
}

\author{
Fengshan Si $\mathbb{D},{ }^{1}$ Zhengkun Yan, ${ }^{2}$ Jing Wang $^{\mathbb{D}},{ }^{1}$ and Daoming Dai ${ }^{1}$ \\ ${ }^{1}$ School of Management Science and Engineering, Anhui University of Finance and Economics, Bengbu 233030, China \\ ${ }^{2}$ School of Languages and Media, Anhui University of Finance and Economics, Bengbu 233030, China \\ Correspondence should be addressed to Jing Wang; crystalstella@126.com
}

Received 23 April 2020; Accepted 18 August 2020; Published 4 September 2020

Academic Editor: Sabri Arik

Copyright (c) 2020 Fengshan Si et al. This is an open access article distributed under the Creative Commons Attribution License, which permits unrestricted use, distribution, and reproduction in any medium, provided the original work is properly cited.

Taking the carbon emissions per unit product as the standard to measure the low-carbon technology level of the enterprise, this article analyzed how the technology supplier enterprises realize low-carbon production and achieve a win-win situation for both supply and demand through technology sharing through technology research and development. Based on the positive effect of low-carbon technology level on product demand, we studied the optimal pricing strategy and the optimal low-carbon technology level in the technology supply enterprises under the Stackelberg game in 3 conditions (i.e., without technology research and development or technology sharing, with technology research and development but no technology sharing, and with both technology research and development and technology sharing). We also drew a comparative analysis of the optimal product price, the optimal low-carbon technology level, and the optimal profit in the three scenarios. Besides, by constructing a delayed differential price game model, we studied the equilibrium strategy of price competition between technology supply and demand companies and the local asymptotic stability of the game system at the equilibrium point. In addition, the effects of delay strategy on game equilibrium strategy, the influence of the degree of adjustment of decision variables on the stability of the game system, and the stability of the game system on the evolution trend of the game are also explored. By comparing and analyzing the game results of the oligopoly enterprises in the stable system and the unstable system, it confirmed that the system instability usually causes serious harm to the enterprise.

\section{Introduction}

Most of the research studies on the development of lowcarbon products focus on low-carbon investment [1], green supply chain [2-4], green product design [5], consumers' purchase awareness of green products $[6,7]$, green product pricing strategy [8], etc. However, resource sharing among enterprises also contributes to the green level of products. Therefore, it is of great practical significance to study the evolutionary behavior of the game and the complex characteristics of the system in the context of resource sharing among oligopolies.

In order to maintain the continuity of production and operation, enterprises need to purchase raw materials, consumables, production equipment, and other resources, but enterprises often face the double pressure of procurement cycle and capital cost. On the one hand, if the enterprise does not purchase in advance, it may cause untimely supply, or even resource shortages, and business interruption; on the other hand, if the enterprise purchases ahead of time, it will occupy funds and pay heavy financial costs. Because of the uncertainty of whether or not to use in the future and how much to use, it also often forms precipitated assets and redundant resources, resulting in waste. The dilemma faced by enterprise resource management is mainly due to the uncertainty of resource usage requirements. For this reason, enterprises that need resources can establish a resource sharing mechanism with other enterprises through resource sharing contracts, and by paying a sharing fee that is far less than the amount of direct purchases. They can obtain guarantees for resource purchases or leases provided by the other party. No need to directly purchase new resources. If the 
enterprise does not need to use the resource in the future, it can abandon the purchase. The enterprise loses only a small amount of sharing fees, but it obtains the same use guarantee as the resource purchased by itself; if the enterprise needs to use the resource in the future, the enterprise can directly purchase or lease the resource at the agreed price, saving inventory management costs and capital costs. Enterprises with relatively redundant resources can share their redundant resources through resource sharing contracts while ensuring their own resource supply. In the process of resource sharing, factors such as the amount of resource sharing, sharing fee, and sharing form directly affect the income of the supply and demand enterprises. Therefore, how to adjust the above parameters to ensure the maximum profit of each enterprise is a topic worthy of study. Low-carbon technology is an important core resource for enterprises. Enterprises with this technology can provide it to other enterprises through a sharing mechanism, thereby obtaining additional benefits and improving the low-carbon production level of the entire industry. Low-carbon technology sharing can be described as a process in which enterprise A with the technology to reduce carbon emissions per unit product obtains transfer benefits by transferring part or all of the low-carbon technology to enterprise $\mathrm{B}$ for a fee and improves the low-carbon production level of enterprise B $[9,10]$. Based on the developmental concept of the sharing economy, this paper attempts to study low-carbon production of products through low-carbon technology sharing among oligopolistic enterprises with coopetition relationship.

With regard to research on technology sharing, Hermosilla and $\mathrm{Wu}$ [11] proposed that a larger downstream market can enable enterprises to increase investment in research and development to promote technological innovation and clarified that a larger market can increase the degree of cooperation between upstream innovators and downstream businessmen based on technology sharing and improve complementary capabilities of the enterprise. Fan et al. [12] studied the optimal technology licensing problem when enterprises faced multiple competitors, and designed a dynamic mechanism to implement license auctions. Ghosh and Saha [13] analyzed the strategy of price competition between two companies in a third country and gave the two companies optimal policies based on technology licensing. Huang and Wang [14] analyzed the benefits of information sharing among manufacturers, distributors, and third parties in a closed-loop supply chain under technology licensing and used the Stackelberg game to obtain an equilibrium strategy under whether information is shared. Blohmke [15] combined technology licensing with sustainable development and proposed incorporating technology complexity assessment into technology transfer mechanisms. Chen et al. [16] constructed a mixed oligopoly model consisting of a public enterprise and two private enterprises, explored the licensing strategy considered by innovative private enterprises, and analyzed the patentees and listed companies, public enterprises, and private enterprises patent licensing relationship. Chen et al. [17] established a Cournot duopoly game model involving two countries and discussed the impact of tariff levels on international technology licensing. Bolatan et al. [18] studied the key factors of technology transfer performance and explored its impact on quality performance and total quality management. Petroni et al. [19] analyzed the research results on space technology transfer strategies and determinants since 2008, explored the space agency's policies and strategies for technology transfer, and discussed the determinants of the operation mechanism and the transfer of space technology to other industrial sectors. Zhang et al. [20] identified the main factors affecting the transfer and diffusion of photovoltaic technology by studying the case of the solar photovoltaic industry. Zhao et al. [21] studied the best technology licensing contract with network effects and analyzed the impact on social welfare when the product innovator was the leader of the game. Huang and Wang [22] studied the closed-loop supply chain model composed of manufacturers, distributors, and third parties under technology licensing and discussed the impact of remanufacturing capacity on supply chain members and environmental sustainability. In addition, Chang et al. [23] and Hattori [24] studied the impact of government incentives and penalties such as taxes and subsidies on technological innovation and technology sharing. Wu and Kao [25] and Zhang et al. [26] studied the technical cooperation research and development, technology sharing, and technology investment issues between original equipment manufacturers, independent remanufacturers, and contract manufacturers. Hong et al. [27] analyzed technology transfer mechanisms such as fixed fees, royalties, and royalties.

Research on the application of delayed decision in the economic field has become more common. The phenomenon of delay inevitably appears in systemic problems. Scholars at home and abroad have considered the effect of delay in economic game models. $\mathrm{Ma}$ and $\mathrm{Tu}$ [28] applied complex dynamics to a macroeconomic model with time delays and found the effects of changes in time-delay parameters on system stability and Hopf bifurcation. Ma and $\mathrm{Wu}$ [29] established a triopoly price game model with delay, analyzed the relationship between the number of time-delay decision-makers and system stability, and explored the effect of time-lag parameters on system stability. Chern et al. [30] considered the positive effect of delay on demand and the negative effect on cost and default risk and obtained sufficient and necessary conditions for the optimal solution of the Nash equilibrium between the supply and demand sides. $\mathrm{Li}$ and $\mathrm{Ma}$ [31] considered the issue of price decision of dualchannel retailers through online channels and traditional channels and analyzed the impact of delayed decisionmaking of dual-channel retailers on the entire system. Ding et al. [32] and Matsumoto and Szidarovszky [33] established a nonlinear Cournot game model based on bounded rationality for nonlinear time-delay dynamics and found that the appropriate time-delay parameters for local and global stability of the system play an important role. Bao and $\mathrm{Ma}$ [34] studied the complex dynamic characteristics of the oligopoly game considering delayed decision-making and product quality and proposed a feasible operation strategy for the enterprise. Gori et al. [35] studied the duopoly output game model with delay strategy and analyzed the impact of 
delay decision on the oligopoly game strategy. Ma and $\mathrm{Si}$ [36] studied the stability of the duopoly price game model in two stages and analyzed the effects of parameters such as delay variables on the stability of the game system. Wang et al. [37] studied the influence of delay decision variables on the stability and complexity of the energy supply and demand system and give the evolutionary trajectory and stability region of the system.

From the literature, it is evident that

(1) Previous research studies on technology sharing rarely focus on specific technological types, not to mention cost dynamic adjustment mechanisms with regard to low-carbon technology $\mathrm{R} \& \mathrm{D}$, low-carbon technology sharing, and technology sharing. To this end, based on the sharing economy concept, this paper analyzes the low-carbon technology R\&D and technology sharing strategies between duopoly companies and proposes a dynamic adjustment mechanism for production costs, in which carbon emission reduction per unit product is used as a standard to measure the low-carbon technology level of the enterprise. This paper then studies the price game behavior of duopoly companies with and without technology research and development and sharing and explores the impact of decision variables on optimal strategies, system stability, and system evolution behavior.

(2) Most of the research studies apply delayed decisionmaking to discrete game systems, but only consider the influence of the decision-making behaviors in the previous period on those in the next. The delay parameter is not set as the key subject in system bifurcation and chaos study. For this reason, this paper analyzes the effect of delay variables on the complexity and evolutionary behavior in the continuous differential price game system.

(3) Findings concentrate on the optimal strategies of enterprises in a single-period static game and analyze the impact of decision variables on the optimal strategies thereafter. However, the price game of an enterprise is a multicycled and iterative strategyadjusting process, in which the two players gradually converge to an equilibrium state after a long time iteration from the initial state of the game. Therefore, this paper simulates the dynamic game process, examines the trajectories of the game, and figures out the reasons for bifurcation and chaos in the game process of oligopoly companies, which contributes to the existing literature.

In addition, based on the differences of low-carbon technology in oligopolistic enterprises, this paper further studies the product pricing strategies of duopolistic enterprises in low-carbon technology $R \& D$ and sharing, by comparing and analyzing the optimal pricing in four conditions, i.e., +/- low-carbon technology R\&D and technology sharing and +/- the delay strategy. Based on the limited rational expectation rules, we construct a delay differential price game model of Stackelberg duopoly and analyze the effects of decision variables such as technology sharing proportion and unit technology sharing fee on the optimal pricing strategy and game system stability from the perspective of system evolution behavior, system stability, and system complexity, as well as analyzing both the optimal game of enterprises under the complete rational expectation rules and the relationship between game strategy and the evolutionary result of enterprise game under the rule of limited rational expectation. We illustrate the chaotic state of the system, the harm of system instability is described, and the relationship between system stability and system evolution behavior, by means of bifurcation graph, attractor graph, time series graph, maximum Lyapunov exponent graph, entropy graph, and other tools.

The rest of this paper is organized as follows. In Section 2, we construct a duopoly game model based on low-carbon technology sharing. In Section 3, we discuss the optimal game strategy in single-period Stackelberg game and the influence of decision variables on the optimal strategy. In Section 4, we analyze the local asymptotic stability and Hopf bifurcation of the multiperiod game model with delay at the equilibrium point and explore the complex dynamic characteristics of the game model. By comparing with the singleperiod game model, the stability region and evolution trend of the system are given. Finally, conclusions are drawn in Section 5 .

\section{Modelling}

This paper explores the pricing strategy of duopoly enterprises based on low-carbon technology sharing. Let duopoly enterprises be Enterprise 1 and Enterprise 2, and their products Product 1 and Product 2, respectively. We assume that Enterprise 1 makes its low-carbon production capacity stronger than Enterprise 2 via low-carbon technology research and development and that both of the two enterprises maximize their profits by sharing low-carbon technology, while effectively improving the green level of tier products.

Before the implementation of low-carbon technology, the production cost per unit of product in Enterprise 1 is $c_{1}$ (including raw material cost, processing cost, and carbon cost), and the carbon emission per unit of product is $e_{10}$. After the implementation of low-carbon technology, the carbon cost per unit of product is $e_{1}\left(e_{1}<e_{10}\right)$. Let $e$ be carbon emission reduction per unit product that is used to measure the level of carbon emission reduction technology of Enterprise 1, so $e=e_{10}-e_{1}$. When the value of $e$ grows bigger, the low-carbon production technology in Enterprise 1 is relatively stronger; otherwise, the technology is weaker.

Say Enterprise 1 is willing to share part of the low-carbon technology $\theta e$ with Enterprise 2 for profit, in which $\theta$ is the low-carbon technology sharing ratio $(0 \leq \theta \leq 1)$. Enterprise 1 adjusts technology sharing fee in accordance with the amount of products produced by Enterprise 2, and technology sharing fee for the unit in Product 2 is $\theta e p_{c}$, where $p_{c}$ is the unit technology sharing fee of Product 2. The production cost of the unit product after technology R\&D of Enterprise 1 is $c_{1}-\eta_{1} e[6,38]$, where $\eta_{1}$ is the influence 
coefficient of unit product carbon emission reduction on cost. The R\&D cost of Enterprise 1 is $\mu e^{2} / 2[1,7]$, where $\mu$ is the $R \& D$ cost coefficient. Only the one-time R\&D cost of Enterprise 1 is considered here, and the unit product that contains technology R\&D cost is not considered. The price of the unit Product 1 after Enterprise 1 technology development is $p_{1}$.

Before technology sharing, the production cost per unit of Product 2 in Enterprise 2 is $c_{2}$ (including raw material cost, processing cost, and carbon cost); the carbon emission per unit Product 2 is $e_{20}$. Enterprise 2 has not implemented low-carbon technology research and development. After accepting technology sharing provided by Enterprise 1, the carbon emission per unit of Product 2 is $e_{2}=e_{20}-\varphi \theta e$, where $\varphi$ is the influence coefficient of unit low-carbon technology on per unit Product 2 to reduce carbon emission. After technology sharing, the production cost of per unit Product 2 is $c_{2}-\eta_{2} \varphi \theta e$, where $\eta_{2}$ is the influence coefficient of per unit Product 2 to reduced unit carbon emission on cost. The price of unit Product 2 after Enterprise 2 completes technology sharing is $p_{2}$.

Due to the guiding role of the government in the development of low-carbon economy and enhanced consumers' recognition of low-carbon products, carbon emission reduction in unit products has a positive effect on product demand, and carbon emission reduction in unit competitive products has a negative effect. Hence, the demand functions of the two enterprises are as follows:

$$
\begin{aligned}
& q_{1}=a-\alpha_{1} p_{1}+\beta_{1} p_{2}+\gamma_{1} e-\delta_{1} \varphi \theta e, \\
& q_{2}=a-\alpha_{2} p_{2}+\beta_{2} p_{1}+\gamma_{2} \varphi \theta e-\delta_{2} e,
\end{aligned}
$$

where $a(a>0)$ is the maximum potential demand for the product; $\alpha_{i}$ is the sensitivity of the product demand to its own price; $\beta_{i}$ is the sensitivity coefficient of product demand to competitive product price; $\gamma_{i}$ is the influence coefficient of carbon emission reduction in unit product on product demand; and $\delta_{i}$ is the influence coefficient of carbon emission reduction in unit competitive product on demand, $i=1,2$.

For the ease of analysis and calculation, the following assumptions are made considering the actual situation:

(1) Enterprise 1 only considers production cost and lowcarbon technology R\&D cost, and Enterprise 2 only considers production cost and technology sharing cost paid to Enterprise 1, other costs of both enterprises eliminated.

(2) Before Enterprise 1 carries out low-carbon technology R\&D and Enterprise 2 completes accept technology sharing, carbon emission per unit product for the two enterprises is the same, i.e., $e_{10}=e_{20}=e_{0}>0$.

(3) For the ease of calculation, we assume $\alpha_{1}=\alpha_{2}=\alpha$, $\beta_{1}=\beta_{2}=\beta, \quad \gamma_{1}=\gamma_{2}=\gamma, \quad \delta_{1}=\delta_{2}=\delta, \quad$ and $\eta_{1}=\eta_{2}=\eta$, so based on the impact on demand, $\alpha>\beta>\gamma>\delta>0$.
(4) Since two enterprises produce homogeneous products, we assume the impact of unit low-carbon technology on the reduction of carbon emissions per unit Product 1 and per unit Product 2 is the same, i.e., $\varphi=1$.

\section{Research on Characteristics of Stackelberg Price Game of Duopoly in a Single Period}

Enterprise 1 has invested in low-carbon technology R\&D and shared technology with Enterprise 2. The two enterprises are in an unequal decision-making position, and Enterprise 1 is dominating decision-making in the price of Product 1, low-carbon technology level, and technology sharing proportion. Enterprise 2 is the follower, basing the price of Product 2 on Enterprise 1 decision. Based on the fact that duopoly enterprises are completely rational decisionmakers, this section studies the optimal strategy of singleperiod Stackelberg game and makes a comparative analysis of the situation-specific strategies to explore the impact of decision variables on the optimal price and optimal profit.

3.1. Without Technology R\&D and Technology Sharing. This situation is called Case 1, where the demand for products is only related to their prices. According to equations (1) and (2), the demand functions of the two enterprises are as follows:

$$
\begin{aligned}
& q_{1}=a-\alpha p_{1}+\beta p_{2}, \\
& q_{2}=a-\alpha p_{2}+\beta p_{1} .
\end{aligned}
$$

The profits of Enterprise 1 and Enterprise 2 are as follows:

$$
\begin{aligned}
& \pi_{1}\left(p_{1}\right)=\left(p_{1}-c_{1}\right) q_{1} \\
& \pi_{2}\left(p_{2}\right)=\left(p_{2}-c_{2}\right) q_{2}
\end{aligned}
$$

Proposition 1. In Case 1, there are only the following optimal prices $p_{1 . n}^{*}$ and $p_{2 . n}^{*}$ that maximize the profits of Enterprise 1 and Enterprise 2:

$$
\begin{aligned}
& p_{1 . n}^{*}=\frac{2 a \alpha+a \beta+2 \alpha^{2} c_{1}-\beta^{2} c_{1}+\alpha \beta c_{2}}{2\left(2 \alpha^{2}-\beta^{2}\right)}, \\
& p_{2 . n}^{*}=\frac{a\left(4 \alpha^{2}+2 \alpha \beta-\beta^{2}\right)+\left(2 \alpha^{2}-\beta^{2}\right) \beta c_{1}+\left(4 \alpha^{2}-\beta^{2}\right) \alpha c_{2}}{8 \alpha^{3}-4 \alpha \beta^{2}},
\end{aligned}
$$

where the subscript $n$ represents the strategy without technology R\&D and technology sharing, and the superscript * represents the optimal strategy.

The proof process of Proposition 1 is shown in Appendix A. In addition, the proof processes of Propositions 2 and 3 are similar to that of Proposition 1, so this paper will not give the proof process thereafter. 
We bring equations (7) and (8) into equations (3) and (6) and obtain the optimal profits of Enterprise 1 and Enterprise 2 as follows:

$$
\begin{aligned}
\pi_{1 . n}^{*}= & \frac{\left(a(2 \alpha+\beta)+c_{1}\left(\beta^{2}-2 \alpha^{2}\right)+\alpha \beta c_{2}\right)^{2}}{16 \alpha^{3}-8 \alpha \beta^{2}} \\
\pi_{2 . n}^{*} & =\frac{\left(a\left(-4 \alpha^{2}-2 \alpha \beta+\beta^{2}\right)+c_{2}\left(4 \alpha^{3}-3 \alpha \beta^{2}\right)+c_{1}\left(\beta^{3}-2 \alpha^{2} \beta\right)\right)^{2}}{16 \alpha\left(\beta^{2}-2 \alpha^{2}\right)^{2}} .
\end{aligned}
$$

3.2. With Technology R\&D and without Technology Sharing. This situation is called Case 2, where Enterprise 1 has improved low-carbon production capacity through technology $\mathrm{R} \& \mathrm{D}$. The carbon emission per unit product decreases by $e$ units, and the enhancement of low-carbon production capacity increases with the market demand of Product 1. Enterprise 2 has neither technology R\&D nor technology sharing, so low-carbon production capacity has not changed, and the demand for products 2 is negatively affected by the low-carbon technology of Enterprise 1. Based on this, the demand functions of the products of the two enterprises are as follows:

$$
\begin{aligned}
& q_{1}=a-\alpha p_{1}+\beta p_{2}+\gamma e \\
& q_{2}=a-\alpha p_{2}+\beta p_{1}-\delta e .
\end{aligned}
$$

The profit functions of the two enterprises are as follows:

$$
\begin{aligned}
\pi_{1}\left(p_{1}, e\right) & =\left(p_{1}-c_{1}+\eta e\right) q_{1}-\frac{\mu e^{2}}{2} \\
\pi_{2}\left(p_{2}\right) & =\left(p_{2}-c_{2}\right) q_{2} .
\end{aligned}
$$

Proposition 2. In Case 2, when $\left(2 \alpha \gamma+2 \alpha^{2} \eta-\beta(\delta+\beta \eta)\right)^{2}+4 \alpha\left(\beta^{2}-2 \alpha^{2}\right) \mu<0$, there are only the following optimal prices $p_{1 . d}^{*}$ and $p_{2 . d}^{*}$ and the optimal low-carbon technology level $e_{d}^{*}$ that maximize two enterprises' respective profits, where the subscript $d$ indicates the optimal strategy in the case of technology ReD without technology sharing. $p_{1 . d}^{*}, e_{d}^{*}$, and $p_{2 . d}^{*}$ are shown in equations (B.1)-(B.3) in Appendix B.

In Case 2, the optimal profit expression of Enterprise 1 and Enterprise 2 is complex, so Proposition 2 no longer gives the final analytic expression, but in the numerical simulation part, the optimal profit will be calculated according to equations (11)-(14) and equations (B.1)-(B.3).

3.3. With Technology R\&D and Technology Sharing. This situation is called Case 3 , and the product demand is related to the product price and low-carbon technology level. The demand function of the products of the two enterprises is as follows:

$$
\begin{aligned}
& q_{1}=a-\alpha p_{1}+\beta p_{2}+\gamma e-\delta \theta e, \\
& q_{2}=a-\alpha p_{2}+\beta p_{1}+\gamma \theta e-\delta e .
\end{aligned}
$$

The profit functions of the two enterprises are as follows:

$$
\begin{gathered}
\pi_{1}\left(p_{1}, e\right)=\left(p_{1}-c_{1}+\eta e\right) q_{1}+p_{c} \theta e q_{2}-\frac{\mu e^{2}}{2}, \\
\pi_{2}\left(p_{2}\right)=\left(p_{2}-c_{2}+\eta \theta e-p_{c} \theta e\right) q_{2} .
\end{gathered}
$$

Proposition 3. In Case 3, when $\Delta_{2}<0$, there are unique optimal prices $p_{1 . s}^{*}$ and $p_{2 . s}^{*}$ and the optimal low-carbon technology level $e_{s}^{*}$ that maximize the profits of the two enterprises, where

$$
\begin{aligned}
\Delta_{2}= & \left(-2 \alpha^{2} \eta+\beta(\delta+\beta \eta-\gamma \theta)+\alpha(-2 \gamma+2 \delta \theta+\beta \eta \theta)\right)^{2} \\
& +4 \alpha\left(-2 \alpha^{2}+\beta^{2}\right) \mu \\
& +8 \alpha^{2} \theta p_{c}\left(\beta \gamma-\alpha \delta+\left(\alpha \gamma+\alpha^{2} \eta-\beta(\delta+\beta \eta)\right) \theta\right. \\
& \left.+\left(-\alpha^{2}+\beta^{2}\right) \theta p_{c}\right),
\end{aligned}
$$

and the subscript s indicates the optimal strategy in the case of technology R\&D and technology sharing. $p_{1 . s}^{*}, p_{2 . s}^{*}$, and $e_{s}^{*}$ are shown in equations (C.1)-(C.3) in Appendix C.

In Case 3, the optimal profit expression of the two enterprises in Proposition 3 is more complex. In this paper, the final analytical expression will not be given again. In the numerical simulation part, the optimal profit is calculated according to equations (15)-(18) and equation (C.1)-(C.3).

3.4. Comparative Analysis of Optimal Strategies. In order to analyze the difference of the optimal strategy in Propositions $1-3$, on the basis of satisfying the constraints in the proposition, the parameter values are as follows: $a=5, \alpha=0.6$, $\beta=0.4, \gamma=0.2, \delta=0.1, c_{1}=0.6, c_{2}=0.8, \theta=0.5, p_{c}=0.25$, $\mu=0.1$, and $\eta=0.1$.

Estimates for the optimal price, the optimal low-carbon technology level, and the optimal profit are shown in Table 1.

Comparing data in Case 1, Case 2, and Case $3\left(p_{c}=0.25\right.$ and $\theta=0.5)$ in Table 1 , it is evident that the price of unit Product 1 increases gradually. On the one hand, since Enterprise 1 has increased the investment in research and development of low-carbon technology, the increase in production cost has led to the rise of price; on the other hand, the two enterprises have jointly improved the lowcarbon level of products via technology sharing, a situation that is similar to the formation of a monopoly of green products, which also has led to the rise in the price. The price of Product 2 is the lowest when Enterprise 1 implements low-carbon technology research and development without technology sharing. Because consumers have low-carbon preferences, improvement in the low-carbon level of Product 1 will inevitably drive Enterprise 2 to maintain market share by lowering the price. 
TABLe 1: Optimal strategies in different cases.

\begin{tabular}{|c|c|c|c|c|c|c|c|}
\hline & $\theta$ & $p_{1}$ & $p_{2}$ & $e$ & $\pi_{1}$ & $\pi_{2}$ & $\pi_{1}+\pi_{2}$ \\
\hline Case 1 & - & 7.61429 & 7.10476 & - & 22.9601 & 23.8500 & 46.8101 \\
\hline Case 2 & - & 11.3691 & 5.92268 & 29.2045 & 44.8106 & 15.7451 & 60.5557 \\
\hline \multirow{12}{*}{ Case 3} & & & & $p_{c}=0.02$ & & & \\
\hline & $\theta=0.2$ & 10.6944 & 6.62843 & 25.9145 & 41.6484 & 23.3855 & 65.0339 \\
\hline & $\theta=0.5$ & 9.93341 & 7.43304 & 22.2382 & 38.0953 & 33.9534 & 72.0487 \\
\hline & $\theta=0.8$ & 9.36829 & 8.04135 & 19.5511 & 35.4735 & 43.2747 & 78.7482 \\
\hline & & & & $p_{c}=0.25$ & & & \\
\hline & $\theta=0.2$ & 12.0274 & 7.46115 & 31.8474 & 49.7254 & 19.5332 & 69.2586 \\
\hline & $\theta=0.5$ & 13.5539 & 10.535 & 38.6767 & 60.8158 & 28.0243 & 88.8401 \\
\hline & $\theta=0.8$ & 16.3573 & 15.7242 & 51.8651 & 80.8998 & 45.4185 & 126.318 \\
\hline & & & & $p_{c}=0.48$ & & & \\
\hline & $\theta=0.2$ & 13.4892 & 8.61767 & 37.1158 & 58.58 & 14.9812 & 73.5612 \\
\hline & $\theta=0.5$ & 17.703 & 15.1923 & 49.7329 & 86.4667 & 14.6601 & 101.127 \\
\hline & $\theta=0.8$ & 23.487 & 25.3541 & 64.1506 & 125.23 & 15.3154 & 140.545 \\
\hline
\end{tabular}

Profits of Enterprise 1 and Enterprise 2 are the largest in Case 3. Therefore, Enterprise 1 will increase technology research and development efforts to improve low-carbon production capacity. At this time, the two enterprises will also have strong willingness to share technology. The profit of Enterprise 2 is the lowest in Case 2. In other words, when the competitors improve the low-carbon production capacity, the enterprise itself must improve the low-carbon level of the products by means of technology research and development or technology sharing; otherwise, the income will drop significantly. Comparing the profit growth rate of the two enterprises, we can find that the profit growth rate of Enterprise 1 is $164.88 \%$, and the profit growth rate of Enterprise 2 is $17.50 \%$. In addition, the profit of Enterprise 1 is initially smaller than that of Enterprise 2, which is much larger than that of Enterprise 2 after technology research and development or technology sharing, and the gap between the profits of the two enterprises is widening. In a word, the implementation of low-carbon technology R\&D and technology sharing in Enterprise 1 is beneficial to both sides of the enterprise, and Enterprise 1 has greater benefits. In the process from Case 1 to Case 3 , the overall profits of the two enterprises have been increasing. Although the profits of the two enterprises are the largest in Case 3, it must be guaranteed by the strong low-carbon production capacity of Enterprise 1, which puts forward higher requirements for the technological research and development ability and economic strength of Enterprise 1.

In addition, when the unit technology sharing fee is low $\left(p_{c}=0.02\right)$, with the increase of technology sharing proportion of Enterprise 1, the profit of Enterprise 1 shows a downward trend while that of Enterprise 2 shows a significant increase. It can be seen that low sharing fee is very unfavorable for Enterprise 1. In this case, Enterprise 1 must implement technology protection policy and refuse or reduce technology sharing. When the unit technology sharing fee is appropriate $\left(p_{c}=0.25\right)$, the increase of technology sharing proportion will cause the profits of the two enterprises to increase at the same time. In this case, the two enterprises achieve a win-win situation through technology sharing. When the unit technology sharing fee is relatively high $\left(p_{c}=0.45\right)$, the increase of technology sharing proportion leads to a significant increase in the profits of Enterprise 1, while Enterprise 2 decreases first and then increases with a small increase, which is not acceptable to Enterprise 2. In short, the two enterprises need to negotiate and coordinate the unit technology sharing fee and technology transfer ratio to maximize their profits. Through the above analysis, we can see that the two enterprises are willing to accept the moderate technology sharing fee and the high technology sharing proportion.

Based on the above analysis, the following conclusions can be drawn:

(1) Enterprises want to obtain high profits through lowcarbon technology R\&D and sharing, and they must increase investment in technology R\&D. At this time, rising product prices are not good for consumers but beneficial for enterprises.

(2) Whether it is a technology supply enterprise or a technology demand enterprise, each gains the most profit in low-carbon technology R\&D and sharing, and the technology supply enterprise's profit is far greater than the technology demand enterprise.

(3) Through low-carbon technology R\&D and sharing among enterprises, not only can their profits be increased, but also the profits of the entire industry can be promoted.

(4) When low-carbon technology is being shared among enterprises, it is affected by two key factors: unit technology sharing fee and technology sharing degree. When the unit technology sharing fee is too low or too high, only one enterprise makes a significant profit. At this time, the unprofitable enterprise will terminate the technology sharing. Only when it is moderate, technology supply and demand enterprises are profitable, and the higher the degree of technology sharing, the greater the profits of both sides. 


\section{Research on the Characteristics of Stackelberg Model with Delay and Price Game of Duopoly in Multiperiod}

Table 1 shows the optimal price, the optimal low-carbon technology level, and the optimal profit of the two enterprises as fully rational decision-makers in Case 3 when $p_{c}=0.25$ and $\theta=0.5$. In the real market, because the enterprise cannot grasp all the market information, this section constructs the multiperiod Stackelberg price game model with delay in Case 3 based on the limited rational decision-making of enterprises, studies the local asymptotic stability of the game system at the equilibrium point and its long-term repeated strategy adjustment process, analyzes the influence of the system stability on the evolutionary behavior of the game, and explores the influence of decision variables on system stability and game strategy.

4.1. Game Model Construction. According to the above analysis, we can get the marginal profit of Enterprise 1 about price $p_{1}$ and low-carbon technology level $e$ and Enterprise 2 about price $p_{2}$ as follows:

$$
\left\{\begin{array}{l}
\frac{\partial \pi_{1}}{\partial p_{1}}=\frac{1}{2 \alpha}\left(\begin{array}{c}
a(2 \alpha+\beta)+e\left(2 \alpha \gamma-2 \alpha^{2} \eta-\alpha(2 \delta+\beta \eta) \theta+\beta(-\delta+\beta \eta+\gamma \theta)\right) \\
+\left(2 \alpha^{2}-\beta^{2}\right) c_{1}+\alpha \beta c_{2}-4 \alpha^{2} p_{1}+2 \beta^{2} p_{1}+2 e \alpha \beta \theta p_{c}
\end{array}\right) \\
\frac{\partial \pi_{2}}{\partial p_{2}}=a-e \delta+e \gamma \theta+\beta p_{1}-\alpha p_{2}-\alpha\left(e \eta \theta-c_{2}+p_{2}-e \theta p_{c}\right) \\
\frac{\partial \pi_{1}}{\partial e}=\frac{1}{2 \alpha}(a(2 \alpha+\beta) \eta-2 e \eta(\beta(\delta-\gamma \theta)+\alpha(-2 \gamma+2 \delta \theta+\beta \eta \theta))-2 e \alpha \mu \\
+\left(2 \alpha \gamma-\alpha(2 \delta+\beta \eta) \theta+\beta(-\delta+\beta \eta+\gamma \theta)-2 \alpha^{2} \eta\right) p_{1} \\
+\alpha \theta\left(a+2 e(-\delta+\beta \eta+\gamma \theta+\alpha \eta \theta)+2 \beta p_{1}\right) p_{c}-2 e \alpha^{2} \theta^{2} p_{c}^{2} \\
+c_{1}\left(\beta(\delta-\gamma \theta)+\alpha(-2 \gamma+2 \delta \theta+\beta \eta \theta)-\alpha \beta \theta p_{c}\right)+\alpha c_{2}\left(\beta \eta-\alpha \theta p_{c}\right)
\end{array}\right.
$$

The decisions of Enterprise 1 and Enterprise 2 on price and Enterprise 1 on low-carbon technology level are usually based on their marginal profits, $\dot{p}_{i}=k_{i} p_{i} \partial \pi_{i} / \partial p_{i}, i=1,2$ and $\dot{e}=k_{3} e \partial \pi_{1} / \partial e$, where $k_{i}$ is the adjustment speed, $i=1,2,3$. If equation (20) is introduced into the above two equations, the dynamic adjustment process of price and lowcarbon technology level can be described as follows [39]:

$$
\left\{\begin{array}{l}
\dot{p}_{1}=k_{1} p_{1}\left(\frac{1}{2 \alpha}\left(a(2 \alpha+\beta)+e \Delta_{6}+\left(2 \alpha^{2}-\beta^{2}\right) c_{1}+\alpha \beta c_{2}-4 \alpha^{2} p_{1}+2 \beta^{2} p_{1}+2 e \alpha \beta \theta p_{c}\right)\right) \\
\dot{p}_{2}=k_{2} p_{2}\left(a-e \delta+e \gamma \theta+\beta p_{1}-\alpha p_{2}-\alpha\left(e \eta \theta-c_{2}+p_{2}-e \theta p_{c}\right)\right) \\
\dot{e}=k_{3} e\left(\frac { 1 } { 2 \alpha } \left(a(2 \alpha+\beta) \eta-2 e \eta\left(\Delta_{5}+\alpha \Delta_{4}\right)+\alpha \theta\left(a+2 e\left(\Delta_{3}+\alpha \eta \theta\right)+2 \beta p_{1}\right) p_{c}-2 e \alpha^{2} \theta^{2} p_{c}^{2}+\alpha c_{2}\left(\beta \eta-\alpha \theta p_{c}\right)\right.\right. \\
\left.\left.\quad+c_{1}\left(\Delta_{5}+\alpha \Delta_{4}-\alpha \beta \theta p_{c}\right)+\Delta_{6} p_{1}\right)-2 e \alpha \mu\right)
\end{array}\right.
$$


where

$$
\begin{aligned}
& \Delta_{3}=-\delta+\beta \eta+\gamma \theta, \\
& \Delta_{4}=-2 \gamma+2 \delta \theta+\beta \eta \theta, \\
& \Delta_{5}=\beta(\delta-\gamma \theta), \\
& \Delta_{6}=2 \alpha \gamma-2 \alpha^{2} \eta-\alpha(2 \delta+\beta \eta) \theta+\beta \Delta_{3} .
\end{aligned}
$$

Enterprise 1 and Enterprise 2 will adopt a delay strategy when making price decisions. They will refer to the current price $p_{i}(t)$ and the historical price $p_{i}\left(t-\tau_{i}\right)$ to decision. $\tau_{i}$ is a delay parameter. The enterprise $i$ refers to the current period price in the decision-making proportion of $w_{i}$, and the proportion of reference historical price is $1-w_{i}, i=1,2$.
According to this description, the delayed decision price of the two products is as follows:

$$
\left\{\begin{array}{l}
p_{1}^{d}=w_{1} p_{1}(t)+\left(1-w_{1}\right) p_{1}\left(t-\tau_{1}\right) \\
p_{2}^{d}=w_{2} p_{2}(t)+\left(1-w_{2}\right) p_{2}\left(t-\tau_{2}\right)
\end{array}\right.
$$

Here, the superscript $d$ indicates the price with delay strategy. In order to facilitate the analysis and calculation, it is assumed that two enterprises refer to the price of the same historical time, that is, $\tau_{1}=\tau_{2}=\tau$. Because the price of the current period is not easy to obtain in time and accurately, only the case of delayed decision-making of the enterprise is considered here, that is, $w_{1}=w_{2}=0$. So far, the Stackelberg differential game model with delay is as follows:

$$
\left\{\begin{array}{l}
\dot{p}_{1}=k_{1} p_{1}\left(\frac{1}{2 \alpha}\left(\left(2 \beta^{2}-4 \alpha^{2}\right) p_{1}(t-\tau)+\left(\Delta_{6}+2 \alpha \beta \theta p_{c}\right) e+a(2 \alpha+\beta)+\left(2 \alpha^{2}-\beta^{2}\right) c_{1}+\alpha \beta c_{2}\right)\right) \\
\dot{p}_{2}=k_{2} p_{2}\left(\beta p_{1}(t-\tau)-2 \alpha p_{2}(t-\tau)+\left(\gamma \theta-\delta+\alpha \theta p_{c}-\alpha \eta \theta\right) e+a+\alpha c_{2}\right) \\
\dot{e}=k_{3} e\left(\frac{1}{2 \alpha}\left(\left(\Delta_{6}+2 \alpha \theta \beta p_{c}\right) p_{1}(t-\tau)+\left(2 \alpha \theta p_{c}\left(\Delta_{3}+\alpha \eta \theta\right)-2 \alpha^{2} \theta^{2} p_{c}^{2}-2 \alpha \mu+a \alpha \theta p_{c}-2 \eta\left(\Delta_{5}+\alpha \Delta_{4}\right)\right)\right) e\right. \\
\left.\quad+a(2 \alpha+\beta) \eta+\alpha c_{2}\left(\beta \eta-\alpha \theta p_{c}\right)+c_{1}\left(\Delta_{5}+\alpha \Delta_{4}-\alpha \beta \theta p_{c}\right)\right)
\end{array}\right.
$$

4.2. Local Asymptotic Stability of Equilibrium Point. The local asymptotic stability of the equilibrium point can be described as follows: when the system moves from the initial state to the final state, although there is disturbance that causes the initial state of the system to deviate within a small range, the final state of the system can return to equilibrium point $[40,41]$. After calculation, the system's positive equilibrium point is $E\left(p_{1}^{*}, p_{2}^{*}, e^{*}\right)$, which is the same as the optimal strategy in Proposition 3. In this section, we study the bifurcation conditions and local asymptotic stability of system (24) at this equilibrium point.

By linearization, the stability of system (24) at the equilibrium point $E\left(p_{1}^{*}, p_{2}^{*}, e^{*}\right)$ is transformed into the stability at the point $(0,0,0)$. The linearized system is as follows:

$$
\left\{\begin{array}{l}
\dot{p}_{1}=k_{1} p_{1}^{*} \Delta_{10} p_{1}(t-\tau)+k_{1} p_{1}^{*} \Delta_{7} e, \\
\dot{p}_{2}=k_{2} p_{2}^{*} \beta p_{1}(t-\tau)-2 k_{2} p_{2}^{*} \alpha p_{2}(t-\tau)+k_{2} p_{2}^{*} \Delta_{8} e, \\
\dot{e}=k_{3} e^{*} \Delta_{7} p_{1}(t-\tau)+k_{3} e^{*} \Delta_{9} e,
\end{array}\right.
$$

Rewrite as

$$
\begin{aligned}
& \Delta_{7}=\frac{1}{2 \alpha}\left(\Delta_{6}+2 \alpha \theta \beta p_{c}\right), \\
& \Delta_{8}=\gamma \theta-\delta+\alpha \theta p_{c}-\alpha \eta \theta, \\
& \Delta_{9}=\frac{1}{2 \alpha}\left(2 \alpha \theta p_{c}\left(\Delta_{3}+\alpha \eta \theta\right)-2 \alpha^{2} \theta^{2} p_{c}^{2}-2 \alpha \mu-2 \eta\left(\Delta_{5}+\alpha \Delta_{4}\right)\right), \\
& \Delta_{10}=\frac{1}{\alpha}\left(\beta^{2}-2 \alpha^{2}\right),
\end{aligned}
$$

The characteristic equation of system (25) is as follows:

$$
\left|\begin{array}{ccc}
\lambda-k_{1} p_{1}^{*} \Delta_{10} e^{-\lambda \tau} & 0 & -k_{1} p_{1}^{*} \Delta_{7} \\
-k_{2} p_{2}^{*} \beta e^{-\lambda \tau} & \lambda+2 k_{2} p_{2}^{*} \alpha e^{-\lambda \tau} & -k_{2} p_{2}^{*} \Delta_{8} \\
-k_{3} e^{*} \Delta_{7} e^{-\lambda \tau} & 0 & \lambda-k_{3} e^{*} \Delta_{9}
\end{array}\right|=0,
$$

Rewrite as

$$
\lambda^{3}+A_{2} \lambda^{2}+\left(B_{2} \lambda^{2}+B_{1} \lambda\right) e^{-\lambda \tau}+\left(C_{1} \lambda+C_{0}\right) e^{-2 \lambda \tau}=0,
$$

where 


$$
\begin{aligned}
& A_{2}=-k_{3} \Delta_{9} e^{*}, \\
& B_{2}=2 \alpha k_{2} p_{2}^{*}-k_{1} \Delta_{10} p_{1}^{*}, \\
& C_{1}=-2 \alpha k_{1} k_{2} \Delta_{10} p_{1}^{*} p_{2}^{*}, \\
& B_{1}=k_{1} k_{3} \Delta_{9} \Delta_{10} e^{*} p_{1}^{*}-k_{1} k_{3} \Delta_{7}^{2} e^{*} p_{1}^{*}-2 \alpha k_{2} k_{3} \Delta_{9} e^{*} p_{2}^{*}, \\
& C_{0}=-2 \alpha k_{1} k_{2} k_{3} \Delta_{7}^{2} e^{*} p_{1}^{*} p_{2}^{*}+2 \alpha k_{1} k_{2} k_{3} \Delta_{9} \Delta_{10} e^{*} p_{1}^{*} p_{2}^{*},
\end{aligned}
$$

Proposition 4. When $\tau=0$, system (24) is locally asymptotically stable if condition (1) is satisfied, where

Condition (1): $A_{2}+B_{2}>0, B_{1}+C_{1}>0, C_{0}>0$, and $\left(A_{2}+B_{2}\right)\left(B_{1}+C_{1}\right)>C_{0}$.

The proof process of Proposition 4 is shown in Appendix D.

Proposition 5. When $\tau=\tau_{0}>0$, the characteristic equation (28) has a pair of pure imaginary root $\pm i \omega_{0}$ when condition (2) is satisfied, where

Condition (2): a polynomial equation $x^{6}+a_{1} x^{5}+a_{2} x^{4}+$ $a_{3} x^{3}+a_{4} x^{2}+a_{5} x+a_{6}=0$ has six positive roots; $a_{1} \ldots a_{6}$ is a positive constant, respectively.

The proof process of Proposition 5 is shown in Appendix E.

Proposition 6. When condition (3) is satisfied, system (24) satisfies the transversality condition of the Hopf bifurcation, where

Condition (3): $Q_{R} P_{R}+Q_{I} P_{I} \neq 0$.

F.

The proof process of Proposition 6 is shown in Appendix

Based on Propositions 4-6, we can get the following conclusion $[42,43]$.

Conclusion 1. According to Propositions 4-6, then when $\tau \in\left[0, \tau_{0}\right)$, system (24) is locally asymptotically stable at equilibrium point $E\left(p_{1}^{*}, p_{2}^{*}, e^{*}\right)$; when $\tau=\tau_{0}$, system (24) experiences Hopf bifurcation; when $\tau>\tau_{0}$, system (24) is unstable.

4.3. Analysis of Dynamic Game Characteristics. In order to describe the evolutionary behavior of the game system and the impact of decision variables on system stability, the parameters are as follows: $k_{1}=0.5, k_{2}=0.5$, and $k_{3}=0.5$, while the rest parameter value in Section 3.4 does not change. However, it is necessary to ensure that the set of parameter values must meet the constraints in Propositions 4-6. At this point, the equilibrium point of system (24) is $\left(p_{1}^{*}, p_{2}^{*}, e^{*}\right)=(13.5539,10.5350,38.6767)$.

4.3.1. In Case Both Enterprises Do Not Adopt a Delay Strategy. After calculation, $A_{2}+B_{2}=14.0506>0, B_{1}+C_{1}$ $=55.0497>0, C_{0}=39.1326>0$, and $\left(A_{2}+B_{2}\right)\left(B_{1}+C_{1}\right)=$ $773.4814>C_{0}$. According to Proposition 4, system (24) is locally asymptotically stable at the equilibrium point $E$ when $\tau=0$. The time series diagrams of the system about price and low-carbon technology level are shown in Figure 1; the attractors' diagrams of profits are shown in Figure 2.

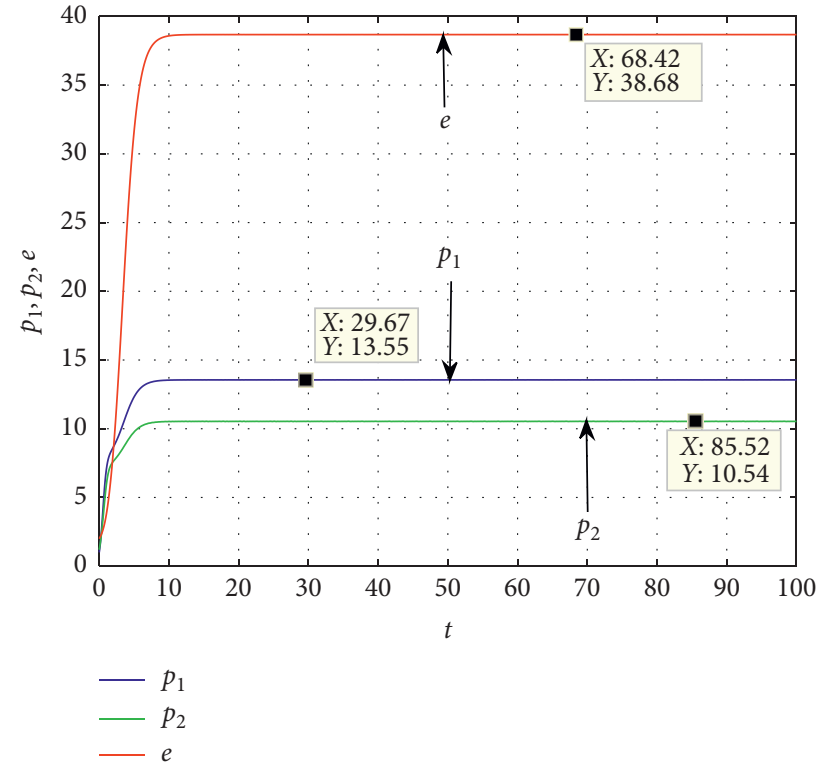

Figure 1: Time series diagram of system when $\tau=0$.

Figure 1 shows that when Enterprise 1 and Enterprise 2 do not adopt the delay strategy, the price and lowcarbon technology level converge to the equilibrium solution after a short adjustment, and the system is stable at this time. Figure 2(a) describes the evolutionary game trajectory of the profits of two enterprises in a stable system. They all converge to the optimal solution in Table 1 . This shows that the optimal strategy in Proposition 3 is obtained by two enterprises after long-term and uninterrupted strategy adjustment and is the result of a repeated game. Figure 2(b) describes the evolution of enterprises' profits when the sensitivity of low-carbon technology increases, from which we can see that enterprises' profits increase significantly with the increase of sensitivity. The evolution process from initial profit to equilibrium profit described in Figure 2 is an effective supplement to Proposition 3.

4.3.2. In Case Both Enterprises Adopt a Delay Strategy. When $\tau>0$, there are two positive roots in equation (E.5), namely, $s_{1}=39.0174$ and $s_{2}=39.9550$. So we get $\omega_{0}=6.2464, \tau_{0}=0.25$, and $Q_{R} P_{R}+Q_{I} P_{I}=152.3378 \neq 0$. According to Conclusion 1, $\tau=\tau_{0}$ is the bifurcation critical value of system (24).

(1) The bifurcation diagram and the largest Lyapunov exponent (LLE for short) diagram of the system with respect to the delay parameter $\tau$ are shown in Figure 3.

Figure 3 shows that the system changes from stable state to unstable state with the increase of $\tau$, and the price and low-carbon technology level converge to equilibrium solution in stable state. It can also be found that the price of Enterprise 2, which is in the position of follower in the game, is prior to the price of Enterprise 1 and the level of low-carbon 


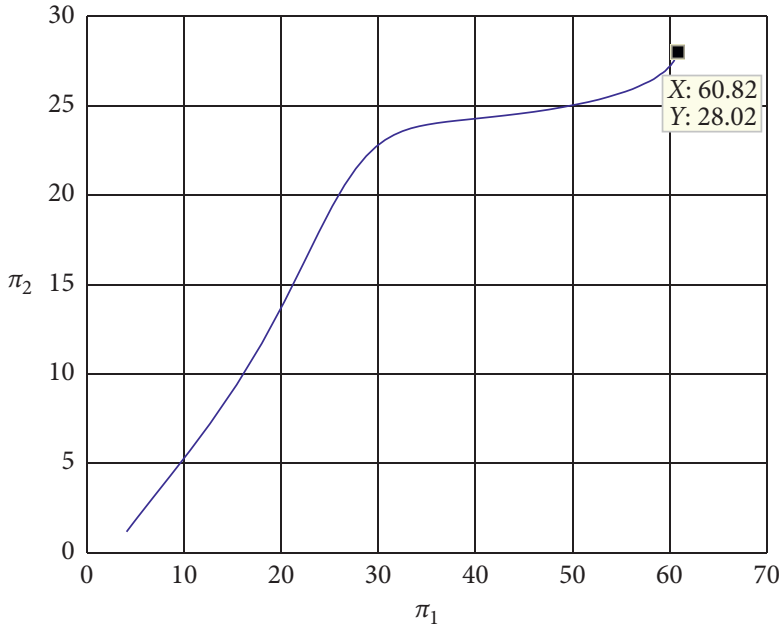

(a)

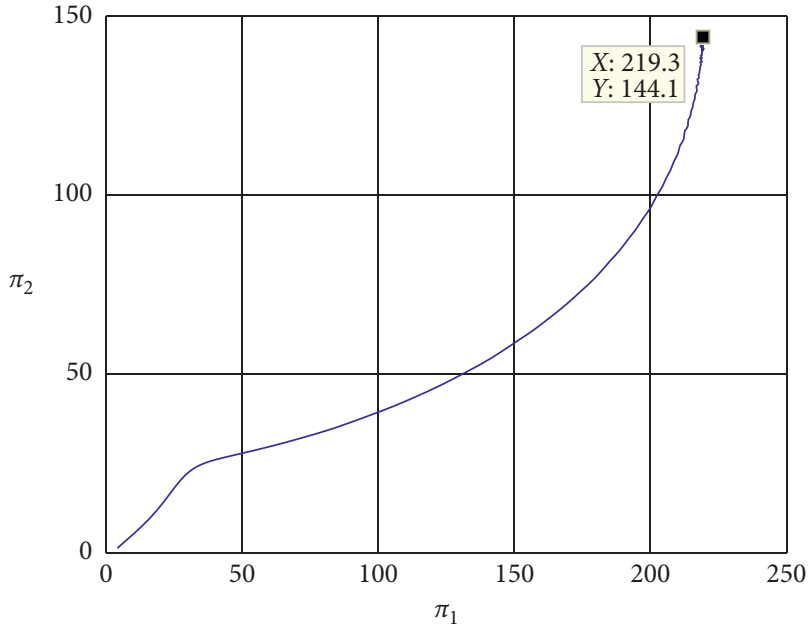

(b)

Figure 2: Attractors of enterprises' profit when $\tau=0$. (a) $\gamma=0.2$ and (b) $\gamma=0.25$.

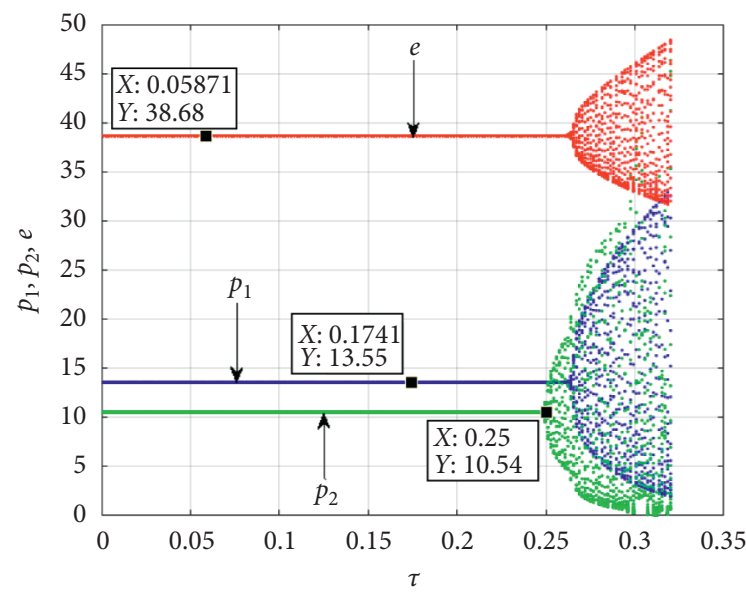

(a)

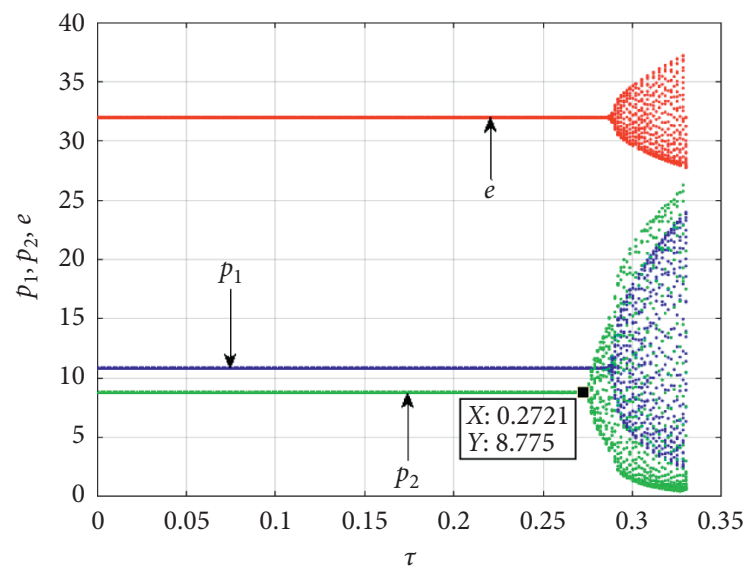

(c)

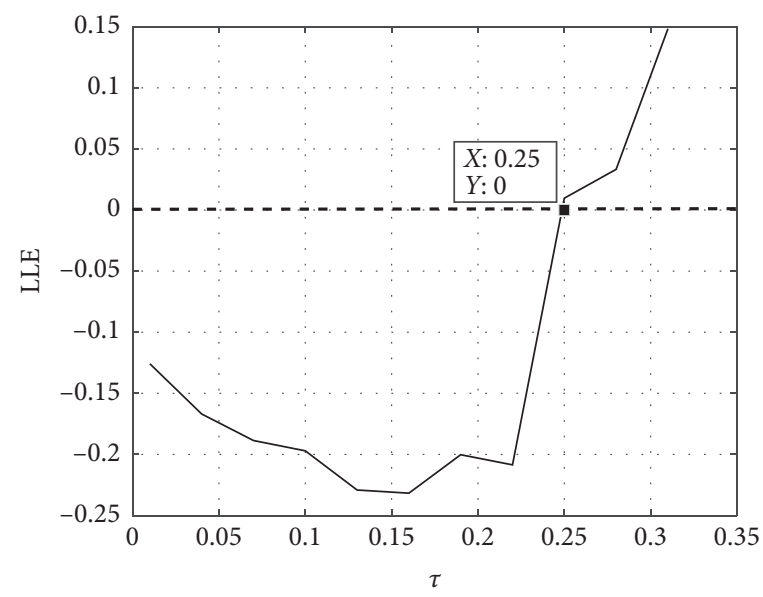

(b)

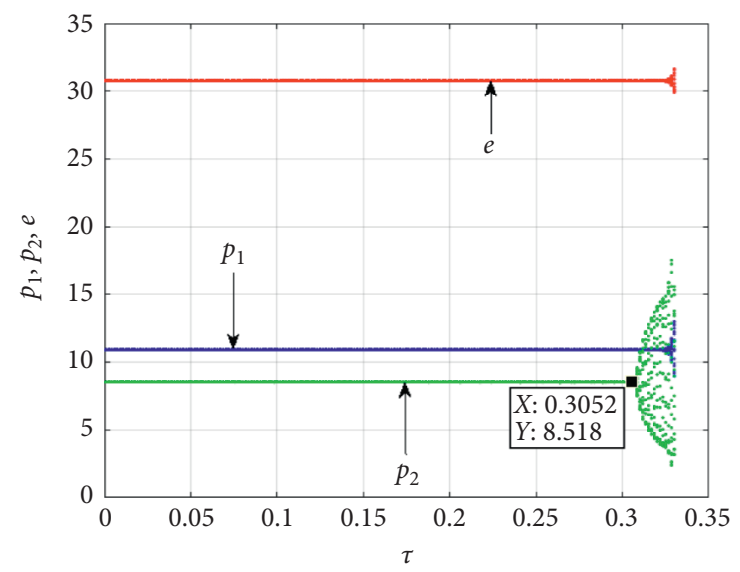

(d)

FIGURE 3: The influence of $\tau$ on the stability of the system; (a, c, d) bifurcation diagrams; (b) the largest Lyapunov exponent diagrams. (a) $a=5, \alpha=0.6$. (b) $a=5, \alpha=0.6$. (c) $a=5, \alpha=0.65$. (d) $a=4, \alpha=0.6$.

technology. It can be seen that the stability of enterprises in leading position is stronger under the same conditions. The largest Lyapunov exponent diagrams of the system further show that the critical value of price bifurcation of Enterprise 2 is $\tau_{0}=0.25$ in Figure 3(b) $[36,37]$. 
The comparison between Figures 3(a) and 3(c) shows that the more sensitive consumers are to the product price ( $\alpha$ increases), the larger the stability region of the system with respect to the delay parameter $\tau$ is when other conditions are constant. That is to say, the more concerned consumers are about the price of products, the earlier historical price can be referred to for enterprise decision-making on the premise of ensuring the stability of the system. By comparing Figures 3(a) and 3(d), it can be found that the reduction of market demand for products under other conditions will also increase the stability region of delay parameters, and the chaos degree of the system will be weaker. However, the reduction of product demand will have a negative impact on the profits of enterprises, as shown in Figure 4.

From Figure 4, it can be seen that in a stable system ( $\tau=0.2<\tau_{0}$, the same below), when the market demand of low-carbon products $a$ gradually increases from 0 to 6 , the profits of both enterprises will increase, and the profit of Enterprise 1 will increase faster. But when the demand exceeds 6 , the profits of both enterprises decrease, and the profit of Enterprise 2 decreases more obviously. The reason is that the demand for low-carbon products affects the R\&D for low-carbon technology level of Enterprise 1. When the demand increases more, Enterprise 1 will improve the $\mathrm{R} \& \mathrm{D}$ low-carbon technology level (according to equation (C.3) in Appendix C). When other conditions remain unchanged, the $\mathrm{R} \& \mathrm{D}$ cost of Enterprise 1 will rise significantly, and the fee that Enterprise 2 needs to pay Enterprise 1 for technology sharing will also increase, so the profits of both enterprises will decrease.

(2) The influence of system stability on evolution behavior of enterprises is shown in Figure 5.

Figure 5 shows that when the game system is stable (as shown in Figures 5(a) and 5(c)), the product price, low-carbon technology level, and enterprises' profit will eventually converge to the equilibrium solution, which is the same as the optimal strategy value in Table 1. The comparison of Figures 1, 5(a), 2(a), and 5(c) shows that, as long as the system is stable, whether the enterprises adopt the delay strategy or not does not affect the equilibrium state of the system evolution, and the evolution trajectory of the profits of the two enterprises is basically the same. But when the system is unstable (as shown in Figures 5(b) and 5(d)), the final result of the system game will tend to be chaotic, which cannot qualify the strategy to satisfy both sides of the game. This shows that maintaining the stability of the system is the basis of the correct decision-making of the enterprise, and the selection of the reference historical price is very important.

(3) In the stable system, the influence of technology sharing fee $p_{c}$ and technology sharing proportion $\theta$ on price $p_{1}$ and $p_{2}$ is shown in Figure 6 .

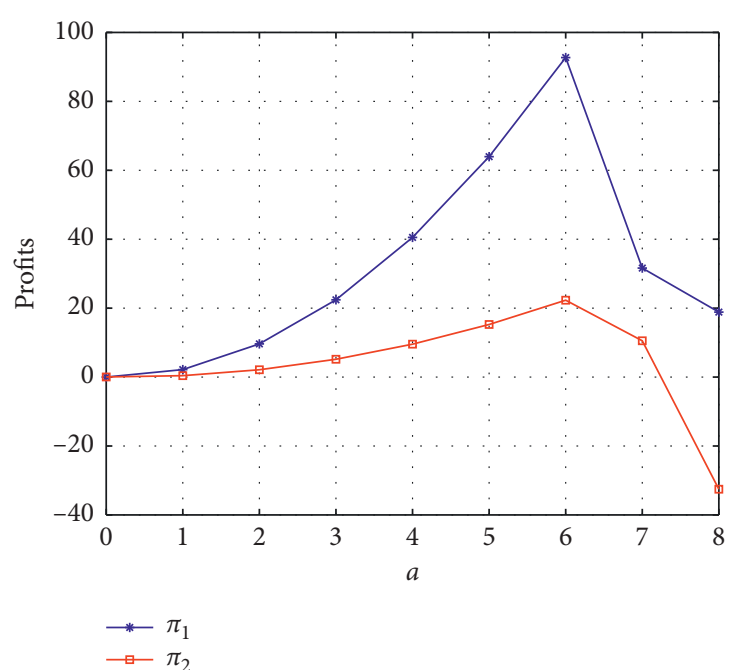

FIGURE 4: The effect of $a$ on the profit of enterprises when $\tau=0.2$ and $\alpha=0.6$.

Comparing Figures 6(a) and 6(b), it is found that the increase of technology sharing fee $p_{c}$ and technology sharing proportion $\theta$ will cause the increase of product price, but the adjustment speed of price $p_{1}$ is slow and the adjustment range is relatively uniform. The reason is that at the beginning of the period, because there are no low-carbon technology R\&D and low-carbon technology sharing in Enterprise 2, it can only improve its competitiveness at a lower price. When technology sharing ratio $\theta$ increases, Enterprise 2 obtains more low-carbon production technologies and the increase of product green degree will inevitably lead to the increase of price. At the same time, Enterprise 1 will also increase the price, so the price of them both will rise. In addition, the continuous increase of technology sharing fee $p_{c}$ will also cause the price of the two products to rise because Enterprise 2 needs to pay more for technology sharing, especially when technology sharing proportion $\theta$ increases, and Enterprise 2 has to increases the price $p_{2}$ as compensation. Therefore, when $p_{c}$ is large and the share ratio is high, the price $p_{2}$ is larger than the price $p_{1}$.

In a word, although increasing technology sharing fee and increasing technology sharing proportion is beneficial to Enterprise 2, the high product sales price is not good for the consumers. The price of the two products has the same change trend, but the adjustment speed of the price $p_{1}$ is slow and the adjustment range is even. The adjustment speed of price $p_{2}$ is first slow then fast, and the adjustment range is first large then small, especially when $p_{c}$ and $\theta$ are large, and the adjustment speed is the fastest, but the adjustment range is the smallest.

(4) The impact of low-carbon technology level $e$ of Enterprise 1 on product price and profit is shown in Figure 7. 


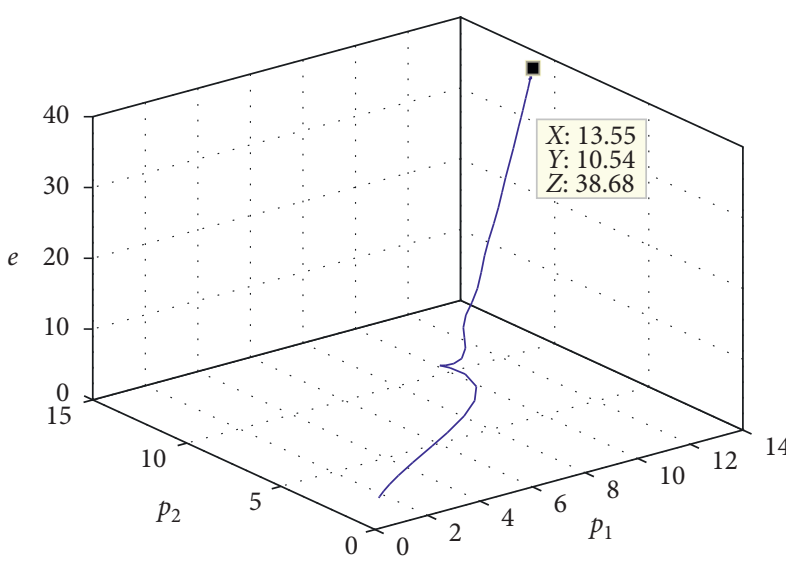

(a)

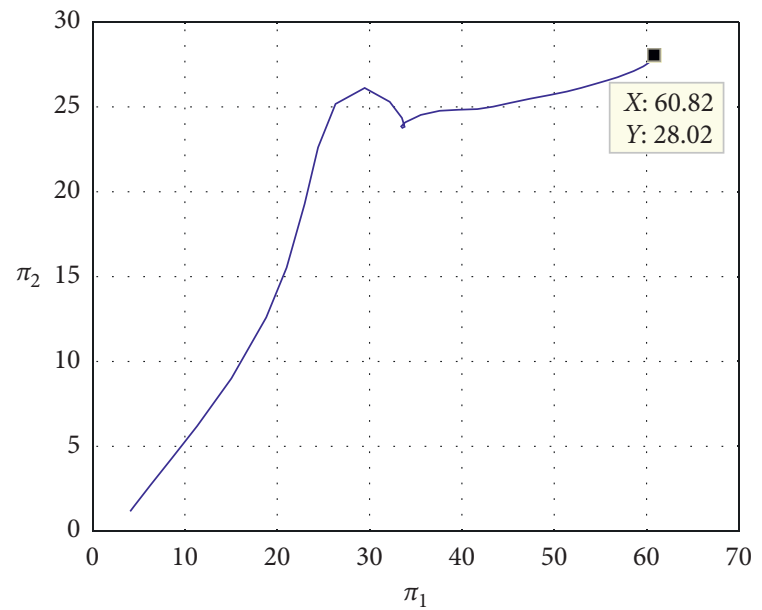

(c)

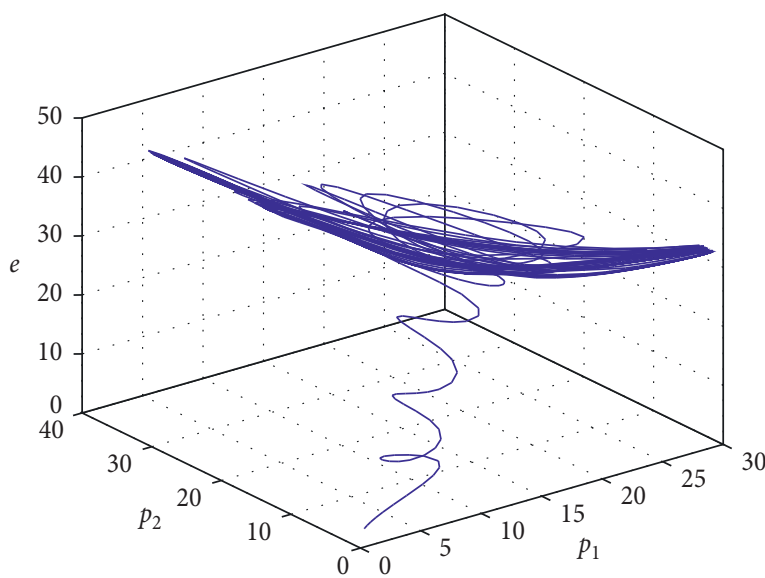

(b)

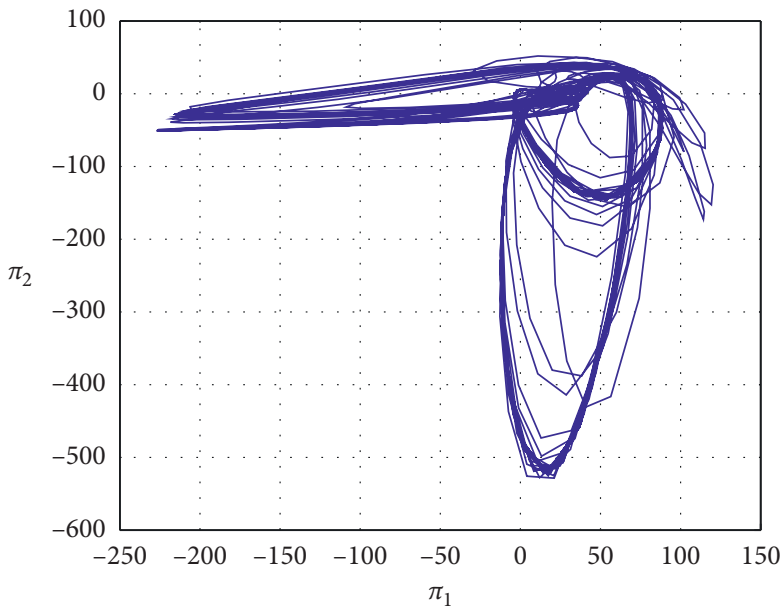

(d)

Figure 5: Attractors for the influence of $\tau$ on game strategy. (a, b) price and low-carbon technical level and (c, d) profit. (a) $\tau=0.2$, (b) $\tau=0.3$, (c) $\tau=0.2$, and (d) $\tau=0.3$.

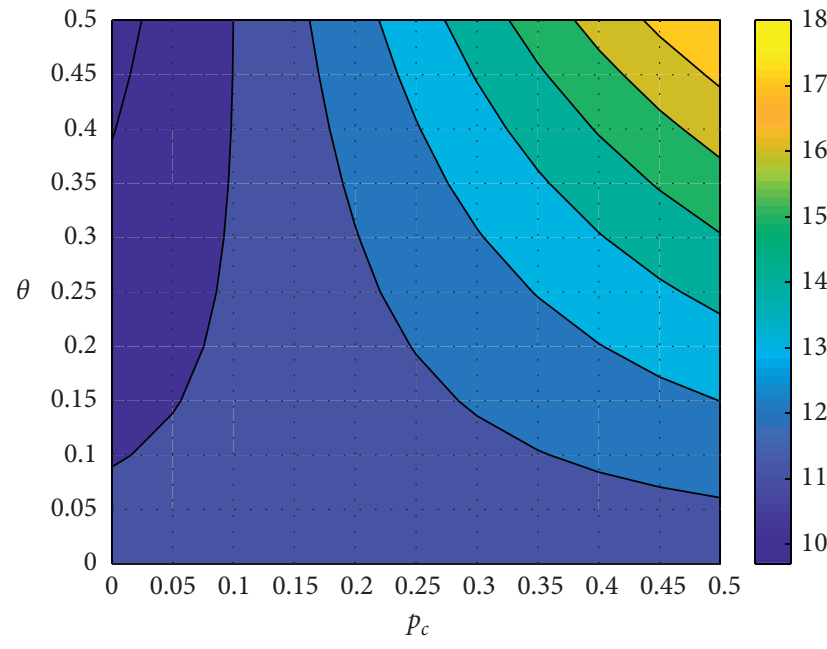

(a)

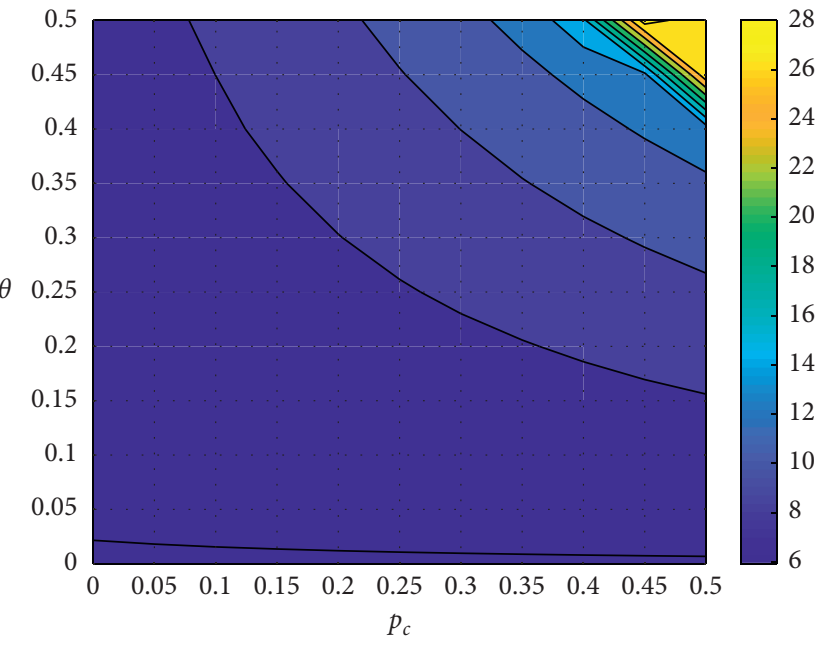

(b)

Figure 6: The influence of $p_{c}$ and $\theta$ on price. (a) $p_{1}$ and (b) $p_{2}$. 


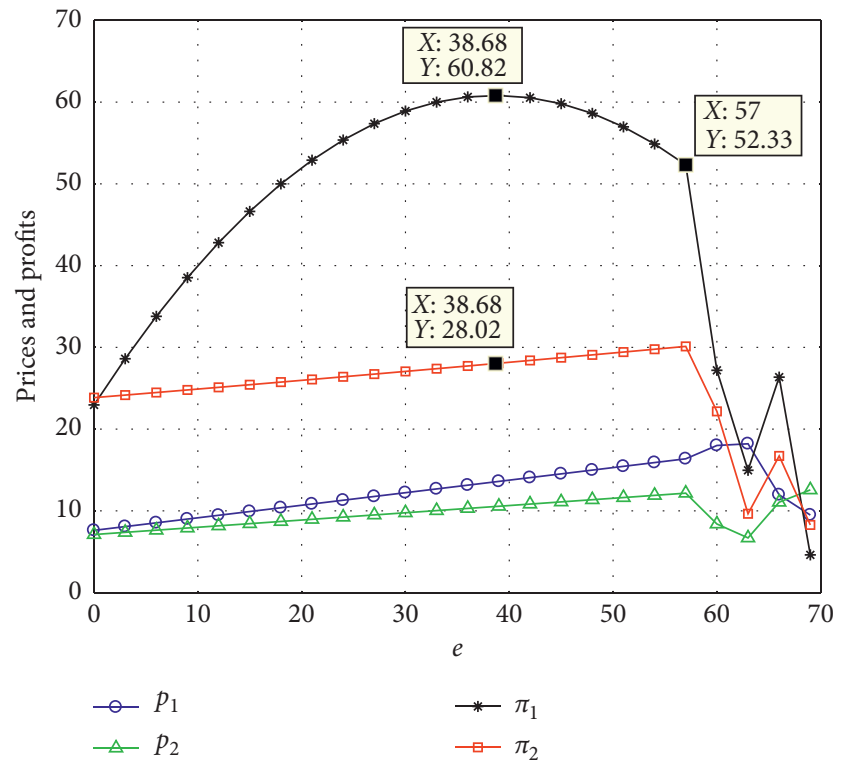

FIgURE 7: The impact of $e$ on prices and profits.

Figure 7 shows that there is an optimal value of lowcarbon technology level of Enterprise 1, which makes the profit of Enterprise 1 the largest, and is the same as the analysis result of Figure 1. In addition, the increase of low-carbon technology level will cause the price and profit to change from stable state to unstable state and the profit will be greatly reduced. The critical value of state change is $e=57$. Obviously, the best value of R\&D low-carbon technology level of Enterprise 1 is $e=38.68$. When $e \in(0,38.68)$, the profits of both enterprises gradually increase with the increase of $e$, and at this time, Enterprise 1 has a strong desire to increase low-carbon $\mathrm{R} \& \mathrm{D}$, and the two enterprises are full of confidence in technology sharing. When $e \in(38.68,57)$, if Enterprise 1 continues to increase $e$, it will be beneficial to Enterprise 2, but Enterprise 1's own interests will be damaged. At this time, Enterprise 1 will lose the power of low-carbon technology R\&D; when $e>57$, the profits of the two enterprises will fall precipitously and enter a disordered state together with the price. At this time, the two enterprises will lose the willingness to cooperate.

In a word, Enterprise 1 cannot adjust the low-carbon technology level blindly, which will not only damage the interests of the enterprise, but also cause the instability of the game system, and will bring harm to the stable development and scientific decisionmaking of the enterprise.

(5) The effect of price adjustment speed $k_{1}$ on system stability and complexity:

In order to maximize profits, enterprises often adjust the sales price of products according to the changes of market conditions. But too frequent price adjustment will also lead to stable market shocks, which will lead to chaos. The influence of the price adjustment speed $k_{1}$ of Enterprise 1 on the stability and complexity of game system is shown in Figure 8.

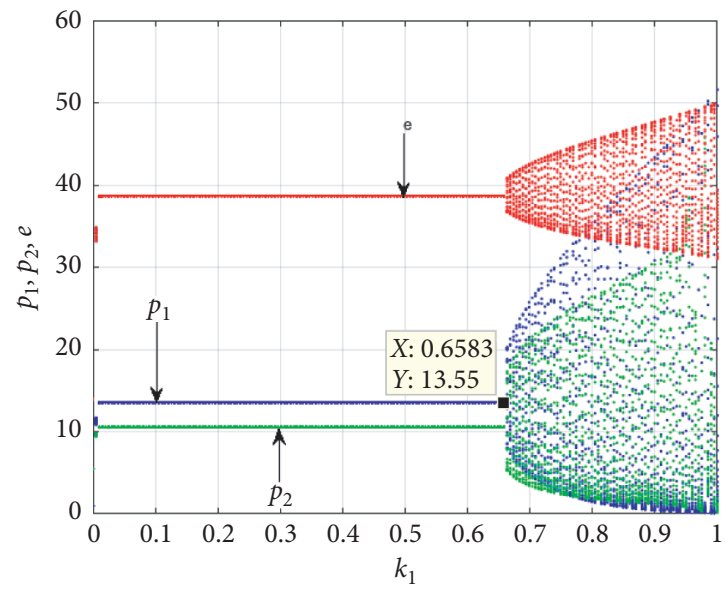

(a)

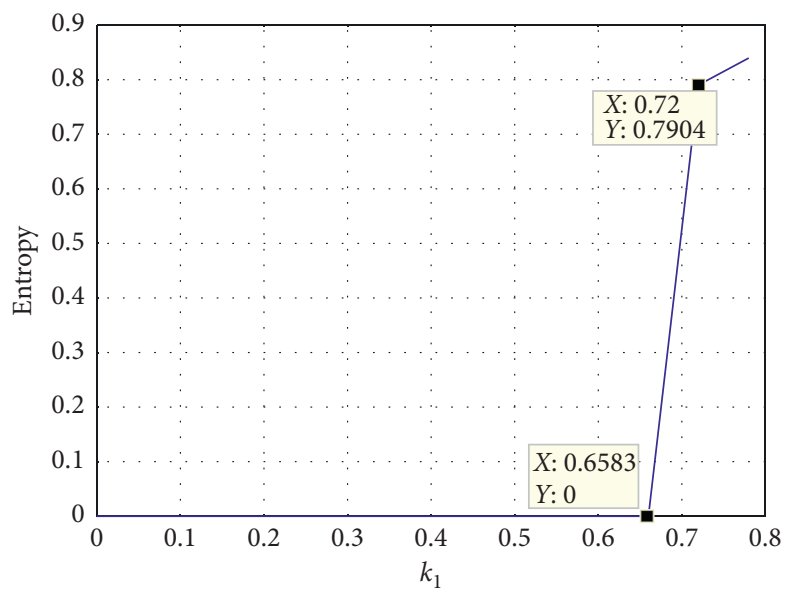

(b)

FIGURE 8: The influence of $k_{1}$ on system stability and complexity. (a) Bifurcation diagram and (b) entropy diagram.

Figure 8 (a) shows that when $k_{1}$ increases from 0 to 0.015 , the price and low-carbon technology level will quickly adjust from the initial state of the game to the equilibrium state, but when $k_{1}=0.6583$, the system will start to produce Hopf bifurcation, and the system will enter the chaotic state of disorder, and the faster the price adjustment speed is, the greater the system vibration amplitude is. In addition, the complexity of the system is also an important factor affecting enterprise decisionmaking. The more stable and simple the system is, the more conducive it is to enterprise decisionmaking. In this paper, entropy diagram is used to describe the complexity of the system. When the entropy value is zero, it means the system is stable; when the entropy value is greater than zero, it means the complexity of the system begins to increase. The larger the entropy value is, the more complex the system is [44]. From Figure 8(b), we can see that the system begins to become complex when $k_{1}=0.6583$, and then the system complexity shows a straight-line rising trend; when $k_{1}=0.72$, 
there is a turning point, and then the increase of the system complexity tends to moderate.

In a word, the speed of price adjustment should not be too fast; otherwise, the system will lose stability and become more complex. In an unstable system, the prices of Product 1 and Product 2 are disorderly interlaced with each other, which makes it difficult for enterprises to grasp the relationship between the decision-makers inside the system and the interaction between the system and the external environment, which brings difficulties to the enterprise decision-making. The influence of $k_{2}$ and $k_{3}$ on the stability of the system is similar to that of $k_{1}$, so we will not discuss it in detail in this paper.

\section{Conclusions}

This paper studies the sharing of low-carbon technology between duopoly enterprises, takes carbon emission reduction per unit product as the standard to measure the R\&D level of low-carbon technology, and analyzes the Stackelberg game model in a single cycle. The optimal strategies in three cases are compared and analyzed; there are no technology R\&D and technology sharing, with technology $\mathrm{R} \& \mathrm{D}$ and no technology sharing, and with technology $\mathrm{R} \& \mathrm{D}$ and technology sharing. The research shows that a high technology sharing ratio and a moderate technology sharing fee between the two enterprises are most beneficial to the two enterprises.

By constructing a differential price game model based on delay decision, this paper discusses the evolution behavior of enterprise game, gives the conditions of system stability, and studies the influence of delay variables, price adjustment speed, low-carbon technology level, and other factors on system stability and game evolution track. The research shows that the price game is a long-term, dynamic process with repeated adjustment of strategy; in a stable system, the change of the initial value of the game does not affect the final equilibrium state of the system; the stable region of the follower enterprise is smaller than that of the leading enterprise, and the follower enterprise first loses stability under the influence of the same parameter change; the more sensitive consumers are to the price of products or the less demand for low-carbon products under the premise of ensuring the stability of the system, the earlier the reference historical price is; in the stable system, the evolution track of the enterprise profit is not affected by the delay strategy; blindly improving the level of low-carbon technology is not only unable to profit, but also easy to cause system instability; changing the speed of price adjustment has a significant impact on the profit of Enterprise 1.

Using the differential game model constructed in this paper, the enterprise can predict the price, low-carbon technology level, and profit at the next moment based on the initial value of the price and low-carbon technology level on the premise of ensuring the stability of the system and adjust the decision variables according to the actual situation, so that the enterprise can get more profits. However, this paper does not take control measures for the unstable system, so we will use the delayed variable feedback control method to effectively control the unstable system in the future and make it return to the stable state.

\section{Appendix}

\section{$\mathbf{A}$}

The proving process of Proposition 1

Proof. According to the inverse solution method, the second partial derivatives of $\pi_{2}\left(p_{2}\right)$ about $p_{2}$ can be obtained by equations (3), (4), and (6). It is $\partial \pi_{2}^{2}\left(p_{1}, p_{2}\right) / \partial p_{2}^{2}=-2 \alpha<0$. Therefore, $\pi_{2}\left(p_{2}\right)$ is a concave function about $p_{2}$, and there is a unique optimal solution $p_{2}^{*}$ to make $\pi_{2}$ maximum, according to $\partial \pi_{2}\left(p_{2}\right) / \partial p_{2}=0$ :

$$
p_{2}=\frac{a+\alpha c_{2}+\beta p_{1}}{2 \alpha}
$$

Taking equation (A.1) into equations (3)-(5), we can get the second partial derivative of $\pi_{1}\left(p_{1}\right)$ about $p_{1}$ as follows: $\partial \pi_{1}^{2}\left(p_{1}\right) / \partial p_{1}^{2}=\left(\beta^{2}-2 \alpha^{2}\right) / \alpha<0$. Similarly, $\pi_{1}\left(p_{1}\right)$ is a concave function about $p_{1}$, that is, there is a unique optimal solution $p_{1}^{*}$ to make $\pi_{1}$ maximum. According to $\partial \pi_{1}\left(p_{1}\right) / \partial p_{1}=0$, we can get

$$
p_{1}^{*}=\frac{2 a \alpha+a \beta+2 \alpha^{2} c_{1}+\alpha \beta c_{2}-\beta^{2} c_{1}}{2\left(2 \alpha^{2}-\beta^{2}\right)} \text {. }
$$

Taking equation (A.2) into (A.1) to get

$$
p_{2}^{*}=\frac{a\left(4 \alpha^{2}+2 \alpha \beta-\beta^{2}\right)+\left(2 \alpha^{2}-\beta^{2}\right) \beta c_{1}+\left(4 \alpha^{2}-\beta^{2}\right) \alpha c_{2}}{8 \alpha^{3}-4 \alpha \beta^{2}} \text {. }
$$

So far, Proposition 1 has been proved.

\section{B}

The optimal strategy of Proposition 2

$$
\begin{gathered}
p_{1 . d}^{*}=\frac{1}{\Delta_{1}}\left(\begin{array}{c}
\left((2 \alpha \gamma-\beta \delta)\left(2 \alpha \gamma+2 \alpha^{2} \eta-\beta(\delta+\beta \eta)\right)+2 \alpha\left(\beta^{2}-2 \alpha^{2}\right) \mu\right) c_{1} \\
+\left(\eta\left(2 \alpha \gamma+2 \alpha^{2} \eta-\beta(\delta+\beta \eta)\right)-2 \alpha \mu\right)\left(a(2 \alpha+\beta)+\alpha \beta c_{2}\right)
\end{array}\right), \\
e_{d}^{*}=-\frac{1}{\Delta_{1}}\left(\left(2 \alpha \gamma+2 \alpha^{2} \eta-\beta(\delta+\beta \eta)\right)\left(a(2 \alpha+\beta)+\left(\beta^{2}-2 \alpha^{2}\right) c_{1}+\alpha \beta c_{2}\right)\right),
\end{gathered}
$$




$$
\begin{aligned}
p_{2 . d}^{*}= & \frac{1}{\Delta_{1}}\left(a\left(2 \alpha^{3} \eta^{2}+2 \alpha^{2}(\eta(2 \gamma+\delta+\beta \eta)-2 \mu)\right)+\beta(-(\delta+\beta \eta)(\gamma+\delta+\beta \eta)+\beta \mu)\right. \\
& \left.+\alpha\left(2 \gamma^{2}+2 \gamma(\delta+\beta \eta)\right)-\beta(\eta(\delta+\beta \eta)+2 \mu)\right) \\
& +\left(-(\beta \gamma-\alpha \delta)\left(\left(-2 \alpha \gamma-2 \alpha^{2} \eta+\beta(\delta+\beta \eta)+\beta\left(\beta^{2}-2 \alpha^{2}\right) \mu\right) c_{1}\right.\right. \\
& \left.\left.+\alpha\left((\gamma+\alpha \eta)\left(2 \alpha \gamma+2 \alpha^{2} \eta-\beta(\delta+\beta \eta)\right)+\left(\beta^{2}-4 \alpha^{2}\right) \mu\right) c_{2}\right)\right),
\end{aligned}
$$

where $\Delta_{1}=\left(2 \alpha \gamma+2 \alpha^{2} \eta-\beta(\delta+\beta \eta)\right)^{2}+4 \alpha\left(\beta^{2}-2 \alpha^{2}\right) \mu$.

The optimal strategy of Proposition 3

$$
\begin{aligned}
& p_{1 . s}^{*}=\frac{1}{\Delta_{2}}\left(\alpha c_{2}\left(-\beta \eta\left(-2 \alpha^{2} \eta+\beta(\delta+\beta \eta-\gamma \theta)\right)+\alpha(-2 \gamma+2 \delta \theta+\beta \eta \theta)\right)\right)-2 \alpha \beta \mu \\
& +\alpha \theta\left(-2 \alpha^{2} \eta+\beta(-3 \delta+\beta \eta+3 \gamma \theta)+\alpha(2 \gamma-2 \delta \theta+\beta \eta \theta)\right) p_{c} \\
& +a\left(\begin{array}{c}
(2 \alpha+\beta)\left(\eta\left(2 \alpha \gamma+2 \alpha^{2} \eta-\alpha(2 \delta+\beta \eta) \theta-\beta(\delta+\beta \eta-\gamma \theta)\right)-2 \alpha \mu\right)+\alpha \theta p_{c} \\
\left(-\beta(\delta+\beta \eta-\gamma \theta)+2 \alpha^{2}(\eta+2 \eta \theta)+\alpha(2 \delta(-2+\theta)+3 \beta \eta \theta+\gamma(-2+4 \theta))-4 \alpha(\alpha+\beta) \theta p_{c}\right. \\
+c_{1}\left(\beta^{2}(\delta-\gamma \theta)(\delta+\beta \eta-\gamma \theta)+\alpha^{2}\left(4 \gamma^{2}\right)\right. \\
+\left(\alpha \beta\left(4 \gamma^{2} \theta+(2 \delta+\beta \eta)^{2} \theta-2 \gamma\left((2 \delta+\beta \eta)(1+\theta)^{2}+2 \beta \mu\right)+\alpha \theta p_{c}\left(4 \alpha^{3} \eta \theta-\beta^{2} \delta+\beta \eta-\gamma \theta\right)\right)\right. \\
\left.+\alpha^{2}(-4 \delta+2 \beta \eta+4 \gamma \theta)+\alpha \beta(6 \gamma-6 \delta \theta-5 \beta \eta \theta)+4 \alpha\left(-\alpha^{2}+\beta^{2}\right) \theta p_{c}\right) z
\end{array}\right) \\
& p_{2 . s}^{*}=\frac{1}{\Delta_{2}}\left(a\left(2 \alpha^{3} \eta^{2}(1+\theta)\right)+\alpha^{2}\left(4 \gamma \eta-\eta\left(\beta \eta\left(-2+\theta+\theta^{2}\right)+2 \delta(-1+\theta(2+\theta))\right)-4 \mu\right)\right. \\
& -\beta\left(\beta \gamma \eta(1-2 \theta)+\gamma \delta(\theta-1)^{2}+\gamma^{2}(\theta-1) \theta+(\delta+\beta \eta)(\delta+\beta \eta-\delta \theta)-\beta \mu\right) \\
& -\alpha\left(2 \gamma^{2}(\theta-1)-2 \delta^{2}(\theta-1) \theta+\beta^{2} \eta^{2}(1+2 \theta)+\beta \delta \eta(1-(\theta-4) \theta)\right. \\
& -2 \gamma\left(\delta(\theta-1)^{2}+\beta \eta\left(1+\theta^{2}\right)\right)+2 \beta \mu+\alpha \theta p_{c}\left(-2 \alpha(\gamma+\delta)+2 \alpha^{2} \eta(-1+3 \theta)\right. \\
& +\alpha(2(\gamma+\delta)+5 \beta \eta) \theta+\beta\left((2 \gamma+\delta+\beta \eta-(\gamma+2 \delta+2 \beta \eta) \theta)-2(3 \alpha-\beta)(\alpha+\beta) \theta p_{c}\right)+c_{1}\left(\alpha^{3} \eta\left(\beta \eta \theta^{2}+2 \delta\left(\theta^{2}-1\right)\right)\right) \\
& \cdot\left(-2 \alpha^{4} \eta^{2} \theta+\alpha \beta(-2 \gamma(3 \delta+\beta \eta)) \theta\right)+\gamma^{2}\left(2+\theta^{2}\right)+\delta\left(\delta+2 \delta \theta^{2}+\beta \eta\left(1+\theta^{2}\right)\right)+\beta^{2}((\delta+\beta \eta-\gamma \theta)(\delta \theta-\gamma)+\beta \mu) \\
& +\alpha \theta p_{c}\left(2 \alpha^{3} \eta-\alpha \beta(3 \delta+\beta \eta-3 \gamma \theta)+\alpha^{2}(2 \gamma-2 \delta \theta+\beta \eta \theta)-2 \beta^{2}(-\gamma+\delta \theta+\beta \eta \theta)+2 \beta(-\alpha+\beta)(\alpha+\beta) \theta p_{c}\right)+\alpha c_{2}\left(2 \alpha^{3} \eta^{2}\right. \\
& +\alpha\left(2 \gamma^{2}-\beta \eta(\delta+\beta \eta)-4 \gamma \delta \theta+\delta(2 \delta+\beta \eta) \theta^{2}\right)-\alpha^{2}(\eta(4 \delta+\beta \eta) \theta+4 \mu-4 \gamma \eta) \\
& +\beta\left(((\delta+\beta \eta-\gamma \theta)(-\gamma+\delta \theta)+\beta \mu)+\theta p_{c}\left(2 \alpha^{3} \eta \theta-2 \alpha^{2}(3 \delta+\beta \eta-3 \gamma \theta)+\beta^{2}(\delta+\beta \eta-\gamma \theta)-\alpha \beta(-4 \gamma+4 \delta \theta+\beta \eta \theta)\right.\right. \\
& \left.+2 \alpha\left(\beta^{2}-\alpha^{2}\right) \theta p_{c}\right) \\
& +\alpha^{2}\left(2 \gamma^{2} \theta+2 \delta^{2} \theta-2 \gamma\left(\delta-\beta \eta+(\delta+\beta \eta) \theta^{2}\right)+\beta\left(\beta \eta^{2} \theta-2 \mu\right)\right) \text {, }
\end{aligned}
$$$$
e_{s}^{*}=-\frac{1}{\Delta_{2}}\left(2 \alpha \gamma+2 \alpha^{2} \eta-\alpha(2 \delta+\beta \eta) \theta-\beta(\delta+\beta \eta-\gamma \theta)\right)\left(a(2 \alpha+\beta)+\left(-2 \alpha^{2}+\beta^{2}\right) c_{1}+\alpha \beta c_{2}\right)+4 \alpha^{2}(\alpha+\beta) \theta\left(\left(a+(-\alpha+\beta) c_{2}\right) p_{c}\right) \text {. }
$$ 
D

The proving process of Proposition 4

Proof. When $\tau=0$, the characteristic equation (28) of system (24) can be simplified as follows:

$$
\lambda^{3}+\left(A_{2}+B_{2}\right) \lambda^{2}+\left(B_{1}+C_{1}\right) \lambda+C_{0}=0 .
$$

According to the Routh criterion, system (24) is locally asymptotically stable when condition (1) is satisfied.

So far, Proposition 4 has been proved.

\section{$\mathbf{E}$}

The proving process of Proposition 5

Proof. The two sides of the characteristic equation (28) are multiplied by $e^{\lambda \tau}$ to get

$$
B_{2} \lambda^{2}+B_{1} \lambda+\left(\lambda^{3}+A_{2} \lambda^{2}\right) e^{\lambda \tau}+\left(C_{1} \lambda+C_{0}\right) e^{-\lambda \tau}=0 .
$$

Suppose $\lambda=i \omega(\omega>0)$ is a root of equation (E.1), which is brought into it, the following can be obtained:

$$
\begin{aligned}
& \left\{\begin{array}{l}
\left(\omega^{3}+C_{1} \omega\right) \sin (\omega \tau)+\left(C_{0}-A_{2} \omega^{2}\right) \cos (\omega \tau)=B_{2} \omega^{2} \\
\left(C_{1} \omega-\omega^{3}\right) \cos (\omega \tau)-\left(C_{0}+A_{2} \omega^{2}\right) \sin (\omega \tau)=-B_{1} \omega
\end{array}\right. \\
& \left\{\begin{array}{l}
\sin (\omega \tau)=-\frac{-\omega^{3} A_{2} B_{1}-\omega^{5} B_{2}+\omega B_{1} C_{0}+\omega^{3} B_{2} C_{1}}{\omega^{6}+\omega^{4} A_{2}^{2}-\omega^{2} C_{1}^{2}-C_{0}^{2}} \\
\cos (\omega \tau)=-\frac{-\omega^{4} B_{1}+\omega^{4} A_{2} B_{2}+\omega^{2} B_{2} C_{0}-\omega^{2} B_{1} C_{1}}{\omega^{6}+\omega^{4} A_{2}^{2}-\omega^{2} C_{1}^{2}-C_{0}^{2}},
\end{array}\right. \\
& \omega^{12}+D_{10} \omega^{10}+D_{8} \omega^{8}+D_{6} \omega^{6}+D_{4} \omega^{4}+D_{2} \omega^{2}+D_{0}=0, \\
& D_{10}=2 A_{2}^{2}-B_{2}^{2} \\
& D_{8}=A_{2}^{4}-A_{2}^{2} B_{2}^{2}-B_{1}^{2}+2 B_{2}^{2} C_{1}-2 C_{1}^{2} \text {, } \\
& D_{6}=4 B_{1} B_{2} C_{0}-A_{2}^{2} B_{1}^{2}-2 A_{2} B_{2}^{2} C_{0}-2 C_{0}^{2}-2 B_{1}^{2} C_{1}+4 A_{2} B_{1} B_{2} C_{1}-2 A_{2}^{2} C_{1}^{2}-B_{2}^{2} C_{1}^{2} \text {, } \\
& D_{4}=2 A_{2} B_{1}^{2} C_{0}-B_{2}^{2} C_{0}^{2}-2 A_{2}^{2} C_{0}^{2}-B_{1}^{2} C_{1}^{2}+C_{1}^{4} \\
& D_{2}=2 C_{0}^{2} C_{1}^{2}-B_{1}^{2} C_{0}^{2} \text {, } \\
& D_{0}=C_{0}^{4} \text {. }
\end{aligned}
$$

Let $s=\omega^{2}$, then equation (E.4) is simplified into

$$
s^{6}+D_{10} s^{5}+D_{8} s^{4}+D_{6} s^{3}+D_{4} s^{2}+D_{2} s+D_{0}=0 .
$$

According to condition (2), there are 6 positive roots $s_{k}$ in equation (E.5), $k=1,2, \cdots, 6$. Then equation (E.4) also has 6 positive roots $\omega_{k}=\sqrt{s_{k}}$. Then, for each $\omega_{k}$, there is a series of $\left\{\tau_{k}^{(j)} \mid k=1,2, \ldots, 6 ; j=0,1, \ldots\right\}$ satisfaction equation (E.1), where $j$ represents the periodic solution of $\tau$. Thus, the result is as follows:

$$
\begin{aligned}
\tau_{k}^{(j)}= & \frac{1}{\omega_{k}} \arccos \left\{-\frac{-\omega_{k}^{4} B_{1}+\omega_{k}^{4} A_{2} B_{2}+\omega_{k}^{2} B_{2} C_{0}-\omega_{k}^{2} B_{1} C_{1}}{\omega_{k}^{6}+\omega_{k}^{4} A_{2}^{2}-\omega_{k}^{2} C_{1}^{2}-C_{0}^{2}}\right\} \\
& +\frac{2 j \pi}{\omega_{k}}, \quad k=1,2, \ldots, 6, j=0,1, \ldots
\end{aligned}
$$

Let $\quad \tau_{0}=\min \left\{\tau_{k}^{(j)} \mid k=1, \ldots, 6 ; j=0,1, \ldots\right\}=\min$ $\left\{\tau_{k}^{(0)} \mid k=1, \ldots, 6\right\}=\tau_{k_{0}}, \omega_{0}=\omega_{k_{0}}$, then we can get

$$
\tau_{0}=\frac{1}{\omega_{0}} \arccos \left\{-\frac{-\omega_{0}^{4} B_{1}+\omega_{0}^{4} A_{2} B_{2}+\omega_{0}^{2} B_{2} C_{0}-\omega_{0}^{2} B_{1} C_{1}}{\omega_{0}^{6}+\omega_{0}^{4} A_{2}^{2}-\omega_{0}^{2} C_{1}^{2}-C_{0}^{2}}\right\},
$$

that is, when $\tau=\tau_{0}$, equation (E.1) has a pair of pure imaginary roots $\pm i \omega_{0}$.

So far, Proposition 5 has been proved.

\section{$\mathbf{F}$}

The proving process of Proposition 6

Proof. The derivative of $\lambda$ with respect to $\tau$ in equation (E.1) is obtained as follows:

$$
\left[\frac{\mathrm{d} \lambda}{\mathrm{d} \tau}\right]^{-1}=\frac{2 B_{2} \lambda+B_{1}+\left(3 \lambda^{2}+2 A_{2} \lambda\right) e^{\lambda \tau}+e^{-\lambda \tau} C_{1}}{-\left(\lambda^{4}+A_{2} \lambda^{3}\right) e^{\lambda \tau}+\left(C_{1} \lambda^{2}+C_{0} \lambda\right) e^{-\lambda \tau}}-\frac{\tau}{\lambda} .
$$

Bring $\lambda=i \omega_{0}$ into equation (F.1), we have 


$$
\operatorname{Re}\left[\frac{\mathrm{d} \lambda}{\mathrm{d} \tau}\right]_{\lambda=i \omega_{0}}^{-1}=\operatorname{Re}\left[\frac{Q_{R}+i Q_{I}}{P_{R}+i P_{I}}\right]=\frac{Q_{R} P_{R}+Q_{I} P_{I}}{P_{R}^{2}+P_{I}^{2}}
$$

where $Q_{R}$ and $P_{R}$ are the real parts of the numerator and denominator, respectively; $Q_{I}$ and $P_{I}$ are the imaginary parts of the numerator and the denominator, respectively:

$$
\begin{aligned}
& Q_{R}=B_{1}-3 \omega_{0}^{2} \cos \left(\omega_{0} \tau_{0}\right)-2 A_{2} \omega_{0} \sin \left(\omega_{0} \tau_{0}\right)+C_{1} \cos \left(\omega_{0} \tau_{0}\right), \\
& Q_{I}=2 B_{2} \omega_{0}-3 \omega_{0}^{2} \sin \left(\omega_{0} \tau_{0}\right)+2 A_{2} \omega_{0} \cos \left(\omega_{0} \tau_{0}\right)-C_{1} \sin \left(\omega_{0} \tau_{0}\right), \\
& P_{R}=-\omega_{0}^{4} \cos \left(\omega_{0} \tau_{0}\right)-A_{2} \omega_{0}^{3} \sin \left(\omega_{0} \tau_{0}\right)-C_{1} \omega_{0}^{2} \cos \left(\omega_{0} \tau_{0}\right)+C_{0} \omega_{0} \sin \left(\omega_{0} \tau_{0}\right), \\
& P_{I}=-\omega_{0}^{4} \sin \left(\omega_{0} \tau_{0}\right)+A_{2} \omega_{0}^{3} \cos \left(\omega_{0} \tau_{0}\right)+C_{1} \omega_{0}^{2} \sin \left(\omega_{0} \tau_{0}\right)+C_{0} \omega_{0} \cos \left(\omega_{0} \tau_{0}\right),
\end{aligned}
$$

If condition (3) is satisfied, system (24) satisfies the transversality condition of the Hopf bifurcation.

So far, Proposition 6 has been proved.

\section{Data Availability}

The numerical simulation data used to support the findings of this study are included within the article.

\section{Conflicts of Interest}

The authors declare no conflicts of interest.

\section{Authors' Contributions}

Fengshan Si proposed research ideas and constructed game models based on low-carbon technology sharing; Zhengkun Yan is responsible for numerical calculation and drawing; Jing Wang suggested research methods and analyzed on the optimal strategy of single-period game model; and Daoming Dai performed the complex characteristics of multiperiod game model with delay. All authors have read and approved the final manuscript.

\section{Acknowledgments}

This work was supported by the Humanities and Social Sciences Research Project of Education Department in Anhui Province (SK2020A0025), the School-level Science Research Project of Anhui University of Finance and Economics (ACKYC20033), and the Natural Science Research Project of Education Department in Anhui Province (KJ2019A0662).

\section{References}

[1] Z. Luo, X. Chen, and X. Wang, "The role of co-opetition in low carbon manufacturing," European Journal of Operational Research, vol. 253, no. 2, pp. 392-403, 2016.

[2] A. Hafezalkotob, "Competition, cooperation, and coopetition of green supply chains under regulations on energy saving levels," Transportation Research Part E: Logistics and Transportation Review, vol. 97, pp. 228-250, 2017.

[3] Z. Hong and X. Guo, "Green product supply chain contracts considering environmental responsibilities," Omega, vol. 83, no. 3, pp. 155-166, 2019.
[4] H. Song and X. Gao, "Green supply chain game model and analysis under revenue-sharing contract," Journal of Cleaner Production, vol. 170, no. 1, pp. 183-192, 2018.

[5] W. Zhu and Y. He, "Green product design in supply chains under competition," European Journal of Operational Research, vol. 258, no. 1, pp. 165-180, 2017.

[6] H. Yang and W. Chen, "Retailer-driven carbon emission abatement with consumer environmental awareness and carbon tax: revenue-sharing versus cost-sharing," Omega, vol. 78, no. 7, pp. 179-191, 2018.

[7] J. Ji, Z. Zhang, and L. Yang, "Carbon emission reduction decisions in the retail-/dual-channel supply chain with consumers' preference," Journal of Cleaner Production, vol. 141, no. 10, pp. 852-867, 2017.

[8] D. Yang and T. Xiao, "Pricing and green level decisions of a green supply chain with governmental interventions under fuzzy uncertainties," Journal of Cleaner Production, vol. 149, no. 4, pp. 1174-1187, 2017.

[9] C. Wu, "Price competition and technology licensing in a dynamic duopoly," European Journal of Operational Research, vol. 267 , no. 6 , pp. 570-584, 2018.

[10] M. Wang, Y. Li, M. Li, W. Shi, and S. Quan, "Will carbon tax affect the strategy and performance of low-carbon technology sharing between enterprises?" Journal of Cleaner Production, vol. 210, no. 2, pp. 724-737, 2019.

[11] M. Hermosilla and Y. Wu, "Market size and innovation: the intermediary role of technology licensing," Research Policy, vol. 47, no. 6, pp. 980-991, 2018.

[12] C. Fan, B. Heon Jun, B. H. Jun, and E. G. Wolfstetter, "Optimal licensing of technology in the face of (asymmetric) competition," International Journal of Industrial Organization, vol. 60, no. 9, pp. 32-53, 2018.

[13] A. Ghosh and S. Saha, "Price competition, technology licensing and strategic trade policy," Economic Modelling, vol. 46, no. 4, pp. 91-99, 2015.

[14] Y. Huang and Z. Wang, "Information sharing in a closedloop supply chain with technology licensing," International Journal of Production Economics, vol. 191, no. 9, pp. 113127, 2017.

[15] J. Blohmke, “Technology complexity, technology transfer mechanisms and sustainable development," Energy for Sustainable Development, vol. 23, no. 12, pp. 237-246, 2014.

[16] Y.-W. Chen, Y.-P. Yang, L. F. S. Wang, and S.-J. Wu, "Technology licensing in mixed oligopoly," International Review of Economics \& Finance, vol. 31, no. 5, pp. 193-204, 2014.

[17] H.-L. Chen, H. Hwang, A. Mukherjee, and P.-C. Shih, "Tariffs, technology licensing and adoption," International Review of Economics \& Finance, vol. 43, no. 5, pp. 234-240, 2016. 
[18] G. I. S. Bolatan, S. Gozlu, L. Alpkan, and S. Zaim, “The impact of technology transfer performance on total quality management and quality performance," Procedia-Social and Behavioral Sciences, vol. 235, no. 11, pp. 746-755, 2016.

[19] G. Petroni, C. Verbano, B. Bigliardi, and F. Galati, "Strategies and determinants for successful space technology transfer," Space Policy, vol. 29, no. 4, pp. 251-257, 2013.

[20] F. Zhang, K. S. Gallagher, and K. S. Gallagher, "Innovation and technology transfer through global value chains: evidence from China's PV industry," Energy Policy, vol. 94, no. 7, pp. 191-203, 2016.

[21] D. Zhao, H. Chen, X. Hong, and J. Liu, “Technology licensing contracts with network effects," International Journal of Production Economics, vol. 158, no. 12, pp. 136-144, 2014.

[22] Y. Huang and Z. Wang, "Closed-loop supply chain models with product take-back and hybrid remanufacturing under technology licensing," Journal of Cleaner Production, vol. 142, no. 1, pp. 3917-3927, 2017.

[23] R.-Y. Chang, H. Hwang, and C.-H. Peng, "Technology licensing, R\&D and welfare," Economics Letters, vol. 118, no. 2, pp. 396-399, 2013.

[24] K. Hattori, "Optimal combination of innovation and environmental policies under technology licensing," Economic Modelling, vol. 64, no. 8, pp. 601-609, 2017.

[25] C.-H. Wu and Y.-J. Kao, "Cooperation regarding technology development in a closed-loop supply chain," European Journal of Operational Research, vol. 267, no. 2, pp. 523-539, 2018.

[26] Q. Zhang, J. Zhang, G. Zaccour, and W. Tang, "Strategic technology licensing in a supply chain," European Journal of Operational Research, vol. 267, no. 1, pp. 162-175, 2018.

[27] H. Xianpei, K. Govindan, X. Lei, and D. Peng, "Quantity and collection decisions in a closed-loop supply chain with technology licensing," European Journal of Operational Research, vol. 256, no. 2, pp. 820-829, 2017.

[28] J. Ma and H. Tu, "Analysis of the stability and hopf bifurcation of money supply delay in complex macroeconomic models," Nonlinear Dynamics, vol. 76, no. 1, pp. 497-508, 2014.

[29] J. Ma and K. Wu, "Complex system and influence of delayed decision on the stability of a triopoly price game model," Nonlinear Dynamics, vol. 73, no. 3, pp. 1741-1751, 2013.

[30] M.-S. Chern, Y.-L. Chan, J.-T. Teng, and S. K. Goyal, "Nash equilibrium solution in a vendor-buyer supply chain model with permissible delay in payments," Computers \& Industrial Engineering, vol. 70, no. 1, pp. 116-123, 2014.

[31] T. Li and J. Ma, "Complexity analysis of the dual-channel supply chain model with delay decision," Nonlinear Dynamics, vol. 78, no. 4, pp. 2617-2626, 2014.

[32] Z. Ding, X. Zhu, and S. Jiang, "Dynamical Cournot game with bounded rationality and time delay for marginal profit," Mathematics and Computers in Simulation, vol. 100, no. 6, pp. 1-12, 2014.

[33] A. Matsumoto and F. Szidarovszky, "Nonlinear cournot duopoly with implementation delays," Chaos, Solitons \& Fractals, vol. 79, no. 10, pp. 157-165, 2015.

[34] B. Bao and J. Ma, "Dynamic game behavior of retailers considering the quality of substitute products based on delay decision," International Journal of Bifurcation and Chaos, vol. 27, no. 13, pp. 1-21, 2017.

[35] L. Gori, L. Guerrini, and M. Sodini, "A continuous time cournot duopoly with delays," Chaos, Solitons \& Fractals, vol. 79, no. 10, pp. 166-177, 2015.
[36] J. Ma and F. Si, "Complex dynamics of a continuous bertrand duopoly game model with two-stage delay," Entropy, vol. 18, no. 266, pp. 1-16, 2016.

[37] J. Wang, F. Si, Y. Wang et al., "Entropy and stability analysis of delayed energy supply-demand model," Entropy, vol. 18, no. 434, pp. 1-21, 2016.

[38] C. D'Aspremont and A. Jacquemin, "Cooperative and noncooperative R\&D in duopoly with spillovers," American Economic Association, vol. 78, no. 5, pp. 1133-1137, 1988.

[39] W. Xu and J. Ma, "Study on the dynamic model of a duopoly game with delay in insurance market," Wseas Transactions on Mathematics, vol. 11, no. 7, pp. 599-608, 2012.

[40] H. Huijberts and C. Withagen, "Local asymptotic stability of optimal steady states," Economics Letters, vol. 40, no. 1, pp. 7-11, 1992.

[41] P. Pucci and S. James, "Local asymptotic stability for dissipative wave systems," Israel Journal of Mathematics, vol. 104, no. 12, pp. 29-50, 1998.

[42] D. D. Hassard, N. D. Kazarinoff, and Y. H. Wan, Theory and Applications of Hopf Bifurcation, Cambridge University Press, Cambridge, UK, 1981.

[43] Y. A. Kuznetsov, Elements of Applied Bifurcation Theory, Springer, New York City, NY, USA, 1998.

[44] J. S. Cánovas and M. Muñoz-Guillermo, "On the complexity of economic dynamics: an approach through topological entropy," Chaos, Solitons \& Fractals, vol. 103, no. 10, pp. 163-176, 2017. 